\title{
Neural networks supporting social evaluation of bodies based on body shape
}

Greven, Inez; Downing, Paul; Ramsey, Richard

\section{Social Neuroscience}

DOI:

$10.1080 / 17470919.2018 .1448888$

Published: 01/05/2019

Peer reviewed version

Cyswllt i'r cyhoeddiad / Link to publication

Dyfyniad o'r fersiwn a gyhoeddwyd / Citation for published version (APA):

Greven, I., Downing, P., \& Ramsey, R. (2019). Neural networks supporting social evaluation of bodies based on body shape. Social Neuroscience, 14(3), 328-344.

https://doi.org/10.1080/17470919.2018.1448888

\footnotetext{
Hawliau Cyffredinol / General rights

Copyright and moral rights for the publications made accessible in the public portal are retained by the authors and/or other copyright owners and it is a condition of accessing publications that users recognise and abide by the legal requirements associated with these rights.

- Users may download and print one copy of any publication from the public portal for the purpose of private study or research.

- You may not further distribute the material or use it for any profit-making activity or commercial gain

- You may freely distribute the URL identifying the publication in the public portal ?
}

Take down policy

If you believe that this document breaches copyright please contact us providing details, and we will remove access to the work immediately and investigate your claim. 
Journal: Social Neuroscience

Title:

Neural networks supporting social evaluation of bodies based on body shape

Running title: Social evaluation of bodies

Inez M. Greven, Paul E. Downing \& Richard Ramsey

Wales Institute for Cognitive Neuroscience, School of Psychology, Bangor University, Bangor, Gwynedd, Wales, LL57 2AS, United Kingdom

Corresponding authors: r.ramsey@bangor.ac.uk 


\begin{abstract}
Body shape cues inferences regarding personality and health, but the neural processes underpinning such inferences remain poorly understood. Across two fMRI experiments, we test the extent to which neural networks associated with body perception and theory-of-mind (ToM) support social inferences based on body shape. Participants observed obese, muscular, and slim bodies that cued distinct social inferences as pilot experiments revealed. To investigate judgment intentionality, the first fMRI experiment required participants to detect repeat presentations of bodies, whereas in fMRI Experiment 2 participants intentionally formed an impression. Body and ToM networks were localized using independent functional localisers. Experiment 1 revealed no differential network engagement for muscular or obese compared to slim bodies. By contrast, in Experiment 2, compared to slim bodies, forming impressions of muscular bodies engaged the body-network more, whereas the ToM-network was engaged more when forming impressions of obese bodies. These results demonstrate that social judgments based on body shape do not rely on a single neural mechanism, but rather on multiple mechanisms that are separately sensitive to body fat and muscularity. Moreover, dissociable responses are only apparent when intentionally forming an impression. Thus, these experiments show how segregated networks operate to extract socially-relevant information cued by body shape.
\end{abstract}

Keywords: functional MRI, body perception, theory-of-mind, body shape 


\section{Introduction}

Social inferences are readily made based on body shape and posture. For instance, emotional states are perceived from body posture (de Gelder, 2006; de Gelder et al., 2010), while health and personality judgments are made based on body size and shape (Borkenau and Liebler, 1992; Musher-Eizenman and Carels, 2009; Naumann et al., 2009; Puhl and Heuer, 2009; Sell et al., 2009; Stulp et al., 2015). Although bodily features cue social inferences, the underlying neural architecture that underpins such social evaluations is far from clear. Indeed, the majority of prior research has focussed on how traits and other social signals are extracted from faces (Todorov et al., 2013). Across two functional magnetic resonance imaging (fMRI) experiments, the current study reveals how distinct brain circuits function in isolation as well as how they interact when socially-relevant cues are available in body shape.

Separate lines of research suggest that at least two distinct brain circuits may contribute to the extraction of social signals from bodies. First, patches of cortex along the ventral visual stream show selective responses for images of bodies compared to faces and to non-social stimuli such as houses and cars (Downing and Peelen, 2011). By extracting body shape and posture cues, signals from the fusiform body area (FBA; Peelen and Downing, 2005; Schwarzlose et al., 2005) and extrastriate body area (EBA; Downing et al., 2001) have been suggested to contribute to social perception (Downing and Peelen, 2011; Quadflieg and Rossion, 2011; Ramsey et al., 2011).

Second, the theory-of-mind network, which encompasses an anterior portion of medial prefrontal cortex, temporoparietal junction and temporal poles, is engaged when reasoning about others' beliefs, desires and attitudes (Frith and Frith, 1999; van Overwalle, 2009) and is anatomically distinct from the body perception network (e.g., Saxe and Kanwisher, 2003). Importantly, the theory-of-mind network is also engaged when making trait inferences about other people, such as whether they are kind, helpful or generous (Mitchell et al., 2005; 
Mitchell, 2009; Ma et al., 2011). Together, these prior studies show that body and theory-ofmind networks have the necessary properties to make complementary contributions to the formation of social inferences based on body shape.

As these prior studies demonstrate, there is compelling evidence for functional segregation in the neural architecture supporting body perception and ToM. Yet if social inferences require integration of perceptual with theory-of-mind representations, this implies that there should be functional integration between these anatomically distinct brain circuits. Indeed, many proposals have suggested that detecting social information from bodies involves a distributed neural network (de Gelder et al., 2010; Quadflieg and Rossion, 2011; Ramsey et al., 2011). Such proposals are consistent with research on face perception, where connectivity studies have revealed that regions along the ventral visual stream form part of a distributed neural network that exchange signals as a function of facial information content (Mechelli et al. 2004; Fairhall and Ishai 2007; He et al. 2015; Hermann et al. 2015; Ishai 2008).

To date, however, research that investigates how the body network exchanges signals with the ToM-network during body perception is limited to two studies (Figure 1). Brain regions associated with theory-of-mind show stronger functional coupling with body-selective patches when observing a body and making a trait-based inference about the person compared to a trait-neutral inference (Greven et al., 2016; Greven and Ramsey, 2017a). These studies suggest that body and ToM networks may exchange signals to form impressions (Greven et al., 2016) and recall previously stored social knowledge (Greven and Ramsey, 2017a).

These prior studies leave several questions unanswered regarding the functional organisation of neural networks that extract social information from body shape. For instance, Greven and colleagues (2016) showed that when seeing an image of a body and reading statements that are trait-diagnostic, such as "She gave money to charity", functional links are 
formed between the ToM-network and body patches. But, social inferences regarding a person's character are not only cued through explicit statements or from prior exposure to an individual; they can also be drawn from body shape alone (Borkenau and Liebler, 1992; Naumann et al., 2009; Puhl and Heuer, 2009).

In addition, not only can trait judgments be based on different inputs such as written statements or body shape, they can also be made with and without an intention to form an impression. Even without an explicit intention to do so, we extract and process social information regarding other people in a spontaneous manner (Uleman et al., 2008). Moreover, prior neuroimaging research has shown that both intentional and spontaneous judgments engage core parts of the theory-of-mind network, but the response for intentional trait judgments engages a more widespread neural network (Ma et al., 2011).

Across two fMRI experiments, therefore, we investigated the extent to which body perception and theory-of-mind networks support social inferences that are based on physical features alone (body shape). Based on two pilot experiments, we selected body images that give rise to distinct social inferences. These included images of muscular and obese individuals, which elicited salient and distinct social judgments, as well as images of slim individuals that were judged in a relatively neutral manner. By comparing images of muscular and obese bodies to slim bodies, we were able to investigate the neural circuits that support different forms of judgment content. Then by manipulating the experimental task across experiments, we investigated inferences that are spontaneously cued by body shape (Experiment 1), as well as inferences that are formed intentionally based on evaluating body shape (Experiment 2).

The overarching hypothesis was that a multi-circuit neural system that spans body perception and theory-of-mind networks would support trait inferences from body shape. We measured neural network engagement in two ways. First, by measuring regional responses in 
body and theory-of-mind networks, we investigated the independent contribution made from within each network. Second, using functional connectivity analyses, we estimated the contribution of functional integration between the two networks (Greven et al., 2016; Greven and Ramsey, 2017a, 2017b). Finding such distributed neural network engagement would reveal a multi-system mechanism by which social inferences about people are extracted from body shape. More generally, as integration between discrete brain circuits is a growing consideration for understanding brain function (Friston and Price, 2001; Sporns et al., 2005; Sporns, 2013) understanding social inference from body shape can be seen as a model problem that speaks to a fundamental question in human neuroscience.

\section{Materials and Methods}

\section{Participants}

Twenty-six participants (13 females; mean $\pm S D$ age: $23.1 \pm 5$ years) completed the first fMRI experiment and twenty-five participants (17 female; mean $\pm S D$ age: $21.1 \pm 4.8$ years) completed the second fMRI experiment. No participants completed both fMRI experiments. All participants were recruited from the Bangor community and received a monetary reimbursement of $£ 15$ for completing the experiment. All participants had normal or corrected-to-normal vision, reported no history of neurological damage and gave informed consent according to the local ethics guidelines. Stimuli were selected and validated for the fMRI experiments in two behavioural pilot experiments, each with a different set of participants. Pilot Experiment 1 involved 14 participants ( 8 females; mean $\pm S D$ age: $19.2 \pm$ 0.8 years) and pilot Experiment 2 involved 23 participants (17 females; mean $\pm S D$ age: 18.8 \pm 0.7 years). None of the individuals in the pilot experiments participated in either of the fMRI experiments. 


\section{Stimuli and experimental procedure}

Overview: Both fMRI experiments involved identical stimuli and a similar blockdesign. The main difference between Experiments 1 and 2 was task instructions. In both experiments, participants completed three tasks during scanning: the main experimental task, a body-localiser and a Theory-of-Mind (ToM) localiser (details of each task are provided below). Each participant's scanning session started with a run of the body-localiser, followed by two runs of the main task. A further body-localiser run and two runs of the main task then followed. Interspersing the body-localiser between runs of the main task was done to vary the experience for participants and offset boredom. Participants then completed two runs of the ToM-localiser. The ToM-localiser was always presented after participants had completed the main task, to ensure that participants were not primed towards making trait inferences during the main task. Stimuli were presented using a desktop PC and Matlab software with Psychtoolbox 3 (www.psychtoolbox.org).

Selection and validation of stimuli: To select and validate stimuli, we ran two behavioural pilot experiments (for full details, see Supplementary Methods). Participants were required to make socially-relevant judgments about silhouettes either presented under unlimited viewing conditions (Pilot 1) or presented briefly and backward masked (Pilot 2). The second pilot experiment was designed to make sure that any differences in ratings were present when participants had minimal exposure to the image and could not rely on a visual after-effect to make a judgment. Participants rated each body on how well a statement matched the body (with 1 being 'not at all' and 9 being 'very much'; Figure 2). Like prior work investigating the evaluation of faces (e.g., Kramer and Ward 2010), statements were taken from measures of Big-5 personality dimensions (Extraversion, Conscientiousness, Agreeableness; Donnellan et al. 2006), as well as physical health (Ware et al., 1996). These four dimensions were chosen to evaluate bodies on because they had been used before to 
assess social judgments of faces (Kramer and Ward 2010) and each dimension related to the kind of trait judgements based on body shape that we aimed to investigate (Puhl and Heuer, 2009). In addition, the agreeableness dimension matched prior work on trait inferences, which typically showed that pro-social and anti-social statements elicit trait inferences and the engagement of the ToM-network more than neutral statements (Greven et al., 2016; Ma et al., 2011; Mitchell et al., 2005).

A series of body images were made that represented three different body shapes: muscular, obese, and slim (40 for Slim, 25 for Muscular and 20 for Obese). Because the focus of our research question was on body shape only, and to stay consistent with the stimuli used in the localiser, we used body silhouettes with heads removed and neutral postures (e.g., no crossed-arms or slouching postures; see Figure 3). Based on prior work, we were confident that stimuli designed in this manner would engage EBA and FBA (Downing et al., 2001; Greven et al., 2016; Urgesi et al., 2007). Slim bodies were selected from Greven et al. (2016), and images of clothed muscular and obese bodies were gathered from various websites and converted into silhouettes and cropped using GIMP 2.8 (www.gimp.org). Stimuli were presented using an iMac computer and Matlab software using Psychtoolbox.

Ratings for each condition were compared using a one-way Analysis of Variance and planned comparisons (slim vs. muscular and slim vs. obese). Therefore, for each judgment type (e.g., Extraversion, Conscientiousness, Agreeableness, Physical Health), a one-way ANOVA was computed to estimate the effect of body type on ratings. Partial eta squared $\left(\eta_{p}^{2}\right)$ was calculated as a measure of effect size for ANOVA. Planned contrasts were performed using paired t-tests. For paired contrasts, $95 \%$ confidence intervals (95\% CI) are reported on the mean difference (Cumming, 2012) and Cohen's $d_{z}$ was calculated as a measure of effect size by dividing the mean difference between conditions by the standard deviation of the difference (Cohen, 1992; Lakens, 2013). 
Results from the ANOVA in the first pilot experiment show that judgments differed among the three body types (all $F \geq 5.11, p \leq .031, \eta_{p}^{2} \geq .28$ ). Paired contrasts showed that in comparison to slim bodies, muscular bodies were rated as more extraverted and healthy, but less agreeable (all Cohen's $d_{z} \geq 0.92$, Figure 3A; Supplementary Table 1). In addition, in comparison to slim bodies, obese bodies were rated as less extraverted, conscientious, and healthy (all Cohen's $d_{z} \geq 0.71$; Figure 3A; Supplementary Table 1). As expected, these results reveal clear differences in social judgements associated with each body category.

To further improve how effective our stimuli are at triggering social inferences, we performed an item-analysis before completing the second pilot experiment. Based on judgments of physical health, we removed 4 slim bodies that were rated outside a middle ("neutral") range (rating <3 and >7), as well as muscular and obese bodies (7 and 2, respectively) that were rated within a middle range (rating $>3$ and $<7$ ). By doing so, we reduced the body database to 72 bodies. In the second pilot experiment, which showed images for a shorter period of time $(330 \mathrm{~ms})$ and backward masked them in order to minimise visual after-effects, we found the identical pattern of results. For each rating scale, ANOVA showed differences among groups (all $F \geq 12.60, p<.001, \eta_{p}^{2} \geq .36$ ). Subsequently, paired contrasts showed that relative to slim bodies, muscular bodies were rated as more extraverted and healthy, but less agreeable (all Cohen's $d_{z} \geq 0.86$, Figure 3B; Supplementary Table 1), while obese bodies were rated as less extraverted, conscientious, and healthy (all Cohen's $\mathrm{d}_{z} \geq 0.99$, Figure 3B; Supplementary Table 1). The second pilot experiment demonstrates that even after a time-limited presentation, the body stimuli cue social inferences in a manner that we expect. Although slim bodies were rated within the "neutral" middle range, we do not suggest that social inferences are not made about slim bodies. We expect social inferences, to some extent, to be made about all social agents and our data only show that muscular and obese bodies are rated to a higher or lower degree than the comparatively neutral slim bodies. 
From the 72 bodies rated in the second pilot experiment, a further 18 images were removed from the Slim condition in order have an equal number of bodies in each condition, resulting in a total of 54 unique bodies. To create more variety of stimuli, mirror-images of all 54 bodies were created by flipping each image along the y-axis. The mirror-reversed and original images were never shown together in the same functional run. Thus, 108 body images were used in the main task of the fMRI experiment.

Main experimental task: For both experiments, the main task used a block-design with blocks of bodies, or a fixation cross. Three different body types were presented, one bodytype per block (Muscular, Obese and Slim). In order to help effectively model the influence of different events on BOLD signal, block order was counterbalanced so that within each run, each condition was preceded equally often by all conditions (Josephs and Henson, 1999; Wager and Nichols, 2003; Aguirre, 2007). To provide a completely balanced block "history" across conditions, each run began with a "starter block", which was not included in further data analysis, as it was not preceded by anything. Subsequently, four further blocks from each condition were presented in a counterbalanced manner (Slim, Muscular, Obese and Fixation). Thus, there were 17 blocks per functional run. Each participant completed 4 runs of this task, with 16 Slim blocks, 16 Muscular blocks, 16 Obese blocks and 16 Fixation blocks across the experiment.

For each image ( $300 \times 650$ pixels) the location of presentation was slightly jittered (4 different locations that varied by 10 pixels around a central fixation dot) to make it more difficult for participants in Experiment 1 from performing the 1-back task based on low-level after-effects from the previous image. From the four options, the location of the image on each trial was randomly selected.

fMRI experiment 1: Once during each body-block, the same image was presented twice in a row and participants were instructed to press a button whenever they detected a 
repetition (1-back recognition task, Downing et al. 2007; Figure 2). Each body image was presented for $500 \mathrm{~ms}$, followed by a blank screen for $1500 \mathrm{~ms}$, resulting in a total of 9 different bodies and 1 repeat per block. Each body-block was 20 seconds in duration, with rest blocks 14 seconds in duration.

fMRI experiment 2: Participants were instructed to form an impression of every body that appeared. To encourage participants to form impressions, at two points throughout a block they would be explicitly asked to rate the last body they had seen. The content of the statement, which could be within the categories of Extraversion, Conscientiousness, Agreeableness, or Physical Health, could not be predicted. The first statement could appear after the $2^{\text {nd }}$ until the $8^{\text {th }}$ image, while the second statement could appear after the $10^{\text {th }}$ until the $17^{\text {th }}$ image. This was randomly decided. Ratings were provided with a button box containing four buttons $(1=$ not at all, $2=$ not that much, $3=$ a little bit, $4=$ very much $)$. Within each block, 18 images were presented for $500 \mathrm{~ms}$ each. On trials that did not involve rating a body, each image was followed by a blank screen for $1000 \mathrm{~ms}$. On trials with a rating, each image was followed with a blank screen for $500 \mathrm{~ms}$, after which a statement with a rating scale appeared on the screen until a response was made or for a maximum of $3000 \mathrm{~ms}$ (Figure 2). If the participant either answered within the time limit or did not respond at all, the experiment would automatically progress. This yielded blocks of varying duration, between 26 and 32 seconds.

Functional localisers: To localise body-selective brain regions we used an established paradigm (Downing et al., 2007; http://pages.bangor.ac.uk/ pss811/page7/page7.html). We presented 12-sec blocks of cars and of whole bodies (without heads). A run started with a blank screen for 14 seconds, followed by two alternations of each condition. This was repeated a second time, and followed by a final rest period of 14 seconds. Each image was presented for $600 \mathrm{~ms}$, followed by a blank screen for $100 \mathrm{~ms}$. Twice during each block, the 
same image was presented twice in a row. Participants had to perform the same task as in the main task for fMRI experiment 1 (1-back task). The image location was slightly jittered in the same way as in the main task. Each participant completed two runs of this task, counterbalancing the order of the stimulus presentation (Bodies or Cars).

To localise brain regions that respond to mental state reasoning, we used an established ToM-localiser (Dodell-Feder et al., 2011; http://saxelab.mit.edu/superloc.php). Participants read 10 short false belief stories, in which the belief characters have about the state of the world is false. Participants also read 10 false photograph stories, where a photograph, map, or sign has out-dated or misleading information. After reading each story, participants had to answer whether the subsequently presented statement is true or false. Each run started with a 12 second rest period, after which the stories and questions were presented for 14 seconds combined (stories: 10 seconds; questions: 4 seconds), and were separated by a 12 second rest period. The order of items and conditions was identical for each subject. In the first run, stimuli 1 - 5 from each condition were presented, and the remaining stimuli were presented during the second block.

\section{Data Acquisition}

Both experiments were conducted on a 3 Tesla scanner (Philips Achieva), equipped with a 32-channel SENSE-head coil. Stimuli were displayed on a MR safe BOLD screen (Cambridge Research Systems: http://www.crsltd.com/) behind the scanner, which participants viewed via a mirror mounted on the head-coil. T2*-weighted functional images were acquired using a gradient echo echo-planar imaging (EPI) sequence. An acquisition time of $2000 \mathrm{~ms}$ was used (image resolution: $3.03 \times 3.03 \times 4 \mathrm{~mm}^{3}, \mathrm{TE}=30$, flip angle $=90^{\circ}$ ). After the functional runs were completed, a high-resolution T1-weighted structural image was acquired for each participant $\left(\right.$ voxel size $=1 \mathrm{~mm}^{3}, \mathrm{TE}=3.8 \mathrm{~ms}$, flip angle $=8^{\circ}, \mathrm{FoV}=288 \times$ 
$\left.232 \times 175 \mathrm{~mm}^{3}\right)$. Four dummy scans $(4 * 2000 \mathrm{~ms})$ were routinely acquired at the start of each functional run and were excluded from analysis, before a further 160 volumes were collected in Experiment 1 and 223 volumes in Experiment 2.

\section{Behavioural analysis}

In the first fMRI experiment, performance on the 1-back task in the main experimental task was measured by calculating the d', i.e., the difference between the z-scores (raw data standardised to normal distribution) for hits and false alarms (Stanislaw and Todorov, 1999). This was compared against 0 for all body type conditions using a one-sample t-test, to see whether the targets (repetitions) could reliably be detected from the noise. To assess whether repetition-detection differed between body types, a comparison across conditions was done using a one-way ANOVA. If the ANOVA revealed a significance difference, paired contrasts were performed.

In the second fMRI experiment, ratings were taken both during and after scanning. During scanning, ratings were recorded on a 4-point scale due to the in-scanner button-box configuration. After scanning, ratings were taken in the same manner as the second pilot experiment. Data were analysed in the same manner as the pilot experiments.

\section{Preprocessing}

Data were preprocessed and analysed using SPM8 (Wellcome Trust Department of Cognitive Neurology, London, UK: www.fil.ion.ucl.ac.uk/spm/). Functional images were realigned, unwarped, corrected for slice timing, and normalized to the MNI template with a resolution of 3x3x3 mm and spatially smoothed using an $8 \mathrm{~mm}$ smoothing kernel. Head motion was examined for each functional run and a run was not analysed further if displacement across the scan exceeded 3 millimetres. In Experiment 1, for the main task data, 
three sessions of 1 participant and one session of 2 participants were removed due to head motion. In Experiment 2, for the main task, one session of 1 participant was removed due to a technical error. In addition, three sessions of 1 participant, two sessions of 2 participants, and one session for 4 participants were removed due to head motion. For the ToM-localiser, data for one participant was corrupted and could not be used.

\section{Overview of analysis strategy}

In both experiments, we used the same three-part strategy. First, independently from the main task, we identified body and theory-of-mind networks using independent functional localisers. Second, we used a univariate model to identify if regional responses in the body and theory-of-mind networks showed a greater response for bodies that cue social inferences compared to neutral inferences (Muscular $>$ Slim and Obese $>$ Slim). Third, we used a measure of functional connectivity (psychophysiological interactions, PPI), to estimate if the coupling between body and theory-of-mind networks was greater for bodies that cue social inferences compared to slim bodies (Muscular $>$ Slim and Obese $>$ Slim).

We calculated the two contrasts separately (Muscular $>$ Slim and Obese $>$ Slim), as our pilot work showed that muscular and obese bodies are perceived differently in terms of trait judgments and physical health and thus they may rely on partially distinct recruitment of body and ToM networks. Given that judgments of obese and muscular bodies related to the same dimensions of personality and health, it is also possible that a common neural network is engaged when making social judgments of obese and muscular bodies compared to slim bodies. To test this latter hypothesis, we also performed a conjunction analysis that tested whether the two contrasts engaged the same neural networks in a similar manner above a set significance threshold $(p<.001, \mathrm{k}=5)$. 
Based on our hypotheses regarding body and theory-of-mind networks, we inclusively masked the contrasts from the main task by body and theory-of-mind localisers (Bodies $>$ Cars and False Beliefs $>$ False Photographs at $p<.001, \mathrm{k}=5$ ). Inclusive masking in this manner makes sure that results from the main analyses are within the body or theory-of-mind networks.

Univariate model and analysis: For the body and ToM localisers, a design matrix was fit for each participant with 2 regressors, one for each experimental condition (bodies and cars; false beliefs and false photographs). Body-selective regions were revealed by contrasting bodies and cars (Bodies > Cars). The ToM-network was revealed by contrasting false beliefs with false photographs (False Beliefs $>$ False Photographs).

For the main task, each condition was modelled from the onset of the first body for a duration of 20 seconds for the first fMRI Experiment and for a variable duration (between 26 and 32 seconds) for the second fMRI Experiment. A design matrix was fit for each participant with 5 regressors in total; one for each body-type ( 3 in total), one for rest blocks, and one for the starter blocks.

Psychophysiological Interaction analysis: Our hypothesis was that the social evaluation of bodies based on body shape would involve functional coupling between distributed neural circuits. Specifically, coupling was predicted between body-selective patches in the ventral visual stream and the ToM-network. To test this hypothesis, we used psychophysiological interaction (PPI) analysis (Friston et al., 1997). PPI enables the identification of brain regions whose activity correlates with the activity of a seed region as a function of a task. Here we used a generalized form of PPI, which allows for comparisons across the complete design space (McLaren et al., 2012). By doing so, it is possible to see whether any voxels across the brain show a correlation with activity in the seed region (the 
"physiological" element) as a function of the two conditions within the main task (the “psychological" element).

The functional localisers were used to define seed regions for the PPI analysis within the body and ToM networks. For the body-localiser, seed regions included right EBA and FBA. We focused on right-sided seed regions because of the greater functional understanding of responses in the right than left hemisphere during body perception (Downing and Peelen, 2011, 2015). For the ToM-localiser, seed regions included bilateral TPJ, bilateral temporal poles (TP), mPFC, and Precuneus. Volumes were generated using a $6 \mathrm{~mm}$ sphere, which was positioned on each individual's seed-region peak.

PPI models for each participant included the 5 regressors from the univariate analyses, as well as 5 PPI regressors. PPI regressors included one for each of the three conditions of the design (Slim, Muscular, Obese), one for the starter block, and one that modelled seed region activity.

To create the PPI regressors, the time series in the seed region was specified as the first eigenvariate, and was consequently deconvolved to estimate the underlying neural activity (Gitelman et al., 2003). Then, the deconvolved time series was multiplied by the predicted, pre-convolved time series of each of the five regressors (4 for the conditions, and 1 for the starter). The resulting PPI for each condition in terms of predicted "neural" activity was then convolved with the canonical haemodynamic response function (HRF) with the time series of the seed region included as a covariate of no interest (McLaren et al., 2012; Spunt and Lieberman, 2012; Klapper et al., 2014). At the second-level analysis, we examined the same contrasts as performed in the univariate analyses (Muscular $>$ Slim; Obese $>$ Slim), as well as the same conjunction analysis of these two contrasts.

For all group-level analyses (univariate and connectivity-based), images were thresholded using a voxel-level threshold of $p<.001$ and a voxel-extent of 5 voxels. Any 
results that survived correction for multiple comparisons at the cluster level (Friston et al., 1994) using a family-wise error (FWE) correction $(p<.05)$ were identified. To localise functional responses we used the anatomy toolbox (Eickhoff et al., 2005).

\section{Results}

fMRI experiment 1:

\section{Behavioural data}

D' differed significantly from zero for all body types (Slim: M=2.68, CI.95 [2.33, 3.02], Cohen's d $d_{z}=3.15$; Muscular: $M=2.81$, CI.95 [2.44, 3.17], Cohen's d $\mathrm{d}_{\mathrm{z}}=3.08$; Obese: $M=2.50$, CI.95 [1.94, 3.06], Cohen's $\mathrm{d}_{\mathrm{z}}=1.81$ ), revealing that participants could reliably detect the task-relevant repetitions of all body types. Additionally, there was no significant difference in performance across different body types $\left(F(2,50)=1.33, p=.27, \eta_{p}^{2}=.051\right)$.

\section{Neuroimaging data}

Functional localiser analyses: For the analysis of both localiser tasks, we report the number of participants that show a response in regions of interest at two different thresholds: $p<.001, \mathrm{k}=5$ and $p<.01, \mathrm{k}=5$ (Supplementary Table 2). The more liberal threshold of $p<0.01$ was used in these localiser analyses to include data from as many participants as possible in subsequent PPI analyses. For the body localiser, the Bodies $>$ Cars contrast revealed clusters in right FBA in 23/26 participants and right EBA in 26/26 participants (Supplementary Table 2). For the ToM localiser, the False Belief $>$ False Photograph contrast revealed clusters in right TPJ in 24/26 participants, left TPJ 25/26 participants, right temporal poles in 26/26 participants, left temporal poles in 25/26 participants, in mPFC in 26/26 participants and in Precuneus in 23/26 participants (Supplementary Table 2).

Main task univariate analyses: We predicted that bodies that cue salient social inferences would engage body and ToM networks more than neutral bodies. However, the 
Muscular $>$ Slim and Obese $>$ Slim contrasts revealed no suprathreshold clusters within the body or ToM networks at the uncorrected threshold $(p<.001, \mathrm{k}=5)$.

Main task Psychophysiological Interaction analyses: We predicted that bodies that cue salient social inferences would engage increased functional coupling between the body and ToM networks more than neutral bodies. For all seed regions tested, the Muscular $>$ Slim and Obese $>$ Slim contrasts revealed no suprathreshold clusters within the body or ToM networks at the uncorrected threshold $(p<.001, \mathrm{k}=5)$.

fMRI experiment 2 :

\section{Behavioural data}

During scanning, due to a technical error, body ratings were not recorded correctly and could not be recovered. After completing the fMRI experiment, participants took part in a further ratings task. Participants rated each body that they had seen previously on a scale from 1 ("not at all") to 9 ("very much") on Extraversion, Conscientiousness, Agreeableness, and Physical Health. For one participant, the post-scanning data did not save and could not be analysed further. The ANOVA showed differences between body types for all rating scales (all $F \geq 15.84, p<.001, \eta_{p}^{2} \geq .41$ ). Paired comparisons showed that in comparison to slim bodies, muscular bodies were rated as more extraverted and healthy, but less agreeable (all $t \geq 3.73$, $p \leq .001$, Cohen'd $\geq 0.91$, Figure 3C; Supplementary Table 1). In addition, obese bodies were rated as less extraverted, conscientious, and healthy (all $t \geq 5.44, p<.001$, Cohen' $\mathrm{d} \geq 1.90$, Figure 3C; Supplementary Table 1). This pattern of results mirrors the results found in both pilot experiments (Figure 3A\&B).

\section{Neuroimaging data}

Functional localiser analyses: For the functional localiser data, we use the same analytical approach as Experiment 1 and report the results in Supplementary Table 3. For the 
body localiser, the Bodies > Cars contrast revealed clusters in right FBA in 20/25 participants and right EBA in 25/25 participants (Supplementary Table 3). For the ToM localiser, the False Belief $>$ False Photograph contrast revealed clusters in right TPJ in 23/24 participants, left TPJ in 22/24 participants, right temporal poles in 23/24 participants, left temporal poles in 23/24 participants, in mPFC in 24/24 participants and in Precuneus in 24/24 participants (Supplementary Table 3).

Main task univariate analyses: When forming impressions of Muscular compared to Slim bodies (Muscular > Slim), two clusters emerged in the body network: Left EBA and right EBA extending into right FBA (Table 1 and Figure 5). Both clusters survived correction for multiple comparisons (FWE-correction $p<.05$ ). No suprathreshold clusters were revealed within the ToM-network.

Conversely, when forming impressions of Obese compared to Slim bodies (Obese > Slim), no suprathreshold clusters emerged within the body-network. However, four clusters did emerge in the ToM-network: bilateral temporal pole and two further clusters in anterior medial prefrontal cortex (Table 1 and Figure 5). As illustrated in Table 1, these clusters in the ToM-network did not remain significant $(p<.05)$ following FWE correction for multiple comparisons. The conjunction of [Muscular $>$ Slim] and [Obese $>$ Slim] showed no common regions of activity.

Main task Psychophysiological Interaction analyses: For all seed regions, when forming impressions of Muscular compared to Slim bodies (Muscular $>$ Slim), there was no increased functional coupling between the body network and ToM-network.

In contrast, when forming impressions of Obese compared to Slim bodies (Obese > Slim), there was increased coupling between the body and ToM networks. Specifically, with right EBA as a seed region, there was increased coupling with right temporal pole (Table 2, 
Figure 6). As illustrated in Table 2, the right temporal pole cluster did not survive FWE correction for multiple comparisons $(p=.32)$.

Open science: Data for all experiments in the current study are available online including behavioural (osf.io/p4sbr) and neuroimaging data (https://neurovault.org/collections/3191/). In addition, to complement the planned analyses that are reported above, we also report percent signal change data using a functional region of interest approach (Supplementary Methods). In order to aid the design of future experiments, these functional region of interest data are also available online (https://osf.io/p4sbr/).

\section{Discussion}

While behavioural research has investigated social inferences based on body size (MusherEizenman and Carels, 2009; Puhl and Heuer, 2009; Sell et al., 2009; Stulp et al., 2015), the neural underpinnings of such inferences are unclear. Across two fMRI experiments, we show that neural networks associated with body perception and ToM make distinct contributions to social perception that depend on the target of a social inference (muscular or obese individual) and the intentionality of the judgment (spontaneous or intentional). These results show a division of labour between body and ToM networks when making social evaluations of bodies based solely on body shape.

\section{Implications for neural circuits subserving person perception}

Prior neuroimaging research has shown that anatomically distinct neural networks show sensitivity to body perception (Downing et al., 2001; Downing and Peelen, 2011) and ToM (Frith and Frith, 1999; Saxe and Kanwisher, 2003; van Overwalle, 2009). More recently, functional interactions between the body perception and ToM networks have been shown when forming links between trait-knowledge and body shape (Greven et al., 2016) and when 
recalling trait knowledge that has previously been associated with specific bodies (Greven and Ramsey, 2017a, 2017b). Here we extend these lines of research to situations where inferences about an individual's character are drawn based solely on body shape in the absence of any other social cue or knowledge.

In the current study, person judgements based on character and health were different (in distinct ways) for obese and for muscular bodies, as compared to slim bodies (MusherEizenman and Carels, 2009; Puhl and Heuer, 2009; Sell et al., 2009; Stulp et al., 2015). In addition, these distinct social appraisals were supported by a division of labour between body perception and ToM networks. Parts of the ToM-network (mPFC and temporal poles) were engaged more when forming an impression of an obese than slim figure, whereas parts of the body network (EBA and right FBA) were engaged more when forming an impression of a muscular than slim figure. In addition, when forming impressions of obese individuals, right EBA showed greater functional coupling with right temporal pole. These results demonstrate dissociable contributions of body perception and ToM networks to social judgments that are cued by different body shapes. Recent behavioural research supports the view that dissociable neural pathways may be responsible for perception of fat and muscle during body perception (Sturman et al., 2017). Sturman and colleagues (2017) showed that visual adaptation towards high body fat biased perception of body fat, but not muscle mass. Likewise, adaptation towards high muscle mass biased perception of muscle mass, but not body fat. The findings from Experiment 2 along with those by Sturman and colleagues (2017), suggest that the perception body of size does not rely on a single neural mechanism, but rather it relies on multiple mechanisms that are separately sensitive to body fat and muscularity (see also Johnstone and Downing, 2017).

The response profile of the body perception network informs understanding of category-selectivity in ventral temporal cortex. The response in EBA and FBA was elevated 
when the task required an explicit social inference of muscular compared to slim bodies, but not when the same bodies were viewed under different conditions (identity recognition Experiment 1). Furthermore, even though obese bodies were physically different in size and shape to slim bodies, there was no additional recruitment of body perception network under any task conditions. These results support the view that category-selectivity in ventral temporal cortex cannot be reduced to task-invariant processing of visual features (Harel et al., 2014; Bi et al., 2016; Peelen and Downing, 2017). Instead, category-selective responses reflect knowledge of what the object means to the observer, as well as how they interact with it (Peelen and Downing, 2017). In the current study, for example, when the goal was to form an impression rather than detect identity, visual processing of body shapes differed. It may be that impressions formed by evaluating cues to physical strength, which have been suggested to be of key evolutionary significance during social interactions (Sell et al., 2009), place greater visual processing demands on accurately distinguishing fine-grained body features. Alternatively, EBA has been shown to be engaged during the aesthetic evaluations of body shape (Calvo-Merino et al., 2010; Cross et al., 2011; Cazzato et al., 2014, 2016), which muscular bodies may trigger more than slim. In contrast, when forming impressions of obese individuals, identification of an obese body based on global shape may be relatively easy and thus reduce the demands on visual processing systems to process fine-grained body features before impressions can be formed.

A different set of results emerged in the ToM-network, which should be treated more cautiously than results in the body network as they did not survive statistical correction for multiple comparisons (Eklund et al., 2016). Even though distinct social inferences were made for obese and muscular bodies, only forming impressions of obese bodies engaged the ToMnetwork. Obese individuals were rated as less extraverted, conscientious and healthy than slim individuals. These judgments are consistent with obesity stigma, which characterises obese 
individuals as lazy, unmotivated, as well as lacking in self-discipline and competence (Puhl and Brownell, 2001; Puhl and Heuer, 2009). By contrast, muscular individuals were rated as more extraverted and healthy, but less agreeable, than slim individuals. Hence, social inferences formed by appraising obese individuals may be associated with a richer store of social knowledge than muscular individuals and thus demand more cognitive processes associated with ToM. Prior neuroscience research has associated the temporal poles with representing and retrieving person knowledge (Olson et al., 2013; Wang et al., 2017) and functional connectivity studies have shown links between the temporal poles and the body perception network when perceptual and inferential information about individuals are integrated (Greven et al., 2016; Greven and Ramsey, 2017a). In addition, mPFC has been associated with making trait inferences (Mitchell et al., 2002, 2005, 2006, Ma et al., 2011, 2014). Therefore, strong and negative person inferences that are commonly associated with obesity, which are not apparent for muscular individuals, may place increasing demands on multiple person knowledge processes such as trait-inference, person memory and/or the integration of multiple person features. At present, however, we are unable to distinguish between these proposals and future research would be required to test them directly.

In contrast to the results when participants intentionally formed an impression of the target person, when the task only required the detection of repeatedly presented bodies, there was no evidence for differential engagement of body and ToM networks. First, these results demonstrate that the intrinsic physical properties of the stimuli cannot account for the results observed in Experiment 2. In addition, the lack of evidence for sensitivity in or between body and ToM networks when the task requires detection of physical features can be interpreted in at least two further ways. One option is that for spontaneous judgments, processes within body and ToM networks are indifferent to body types and operate the same when observing socially salient (obese, muscular) or less salient bodies (slim). Under this view, spontaneous 
judgments require a less elaborate set of cognitive processes, which would apply equally to all body types. Consistent with this interpretation, prior studies that have shown functional interplay between body-selective and extended neural networks have used tasks that focus on social dimensions of bodies (Quadflieg et al., 2011; Greven et al., 2016; Greven and Ramsey, 2017a, 2017b). A second option is that Experiment 1 represents a type-II error. Indeed, it may be that Experiment 1 was not sensitive enough to detect the effects under investigation. Future neuroimaging studies that use more sensitive measures such as multi voxel pattern analysis (Norman et al., 2006; Kriegeskorte et al., 2008), may be able to further probe the functional organisation of body and ToM networks during person perception (Wang et al., 2017). What seems clear based on the current study, however, is that the effect sizes associated with univariate and functional connectivity measures are larger when intentionally forming impressions of other people than when detecting repeat presentations of the same body.

Findings from the current study suggest that intentionally making social inferences from bodies recruits a multi-circuit neural architecture that depends on social content. When task instructions do not require a social judgment, other bodily features may dominate (such as sex and physical identity), which are not as relevant for personality and health judgments and do not engage body or ToM networks. However, when the task changes, the status of personality and health judgments may be elevated in priority compared to other factors (such as sex and physical identity), which recruits body and ToM networks as well as integration between them. Currently this proposal remains speculative, however, and needs to be directly tested by future research.

\section{Limitations and movement towards a more reproducible Social Neuroscience}

Some results in the current study such as those based on functional connectivity do not survive correction for multiple comparisons, which renders them more likely to reflect false 
positives (Eklund et al., 2016). Consequently, we recommend that such findings are treated cautiously as they require replication and confirmation. In addition, anterior temporal and ventral frontal regions suffer from signal dropout during fMRI, which harms the chances of detecting effects in these areas. We do, however, find results in these regions, which may suggest that our data underestimate the size of effects in these regions. To investigate the role of the ToM network in body perception further, future studies may choose to adopt scanning protocols that aim to reduce signal dropout in these areas via the use of shorter echo times, for example (Visser et al., 2009). It is worth noting that we did take several steps to improve rigour in the current study with the aim of building a cumulative platform for studying social neuroscience. After validating stimuli in two behavioural experiments, we conducted two separate fMRI experiments each with 25 or more participants (albeit different sets of participants, since the two studies were not performed immediately after each other). We also retested the stimuli in a post-fMRI behavioural experiment. In addition, by using functional localisers to independently identify separate functional networks, we could directly target neural networks in individual participants, as well as demonstrate clear a priori predictions. Finally, to aid meta-analyses and future experimental design, the data for both experiments are freely available online. 


\section{Acknowledgments}

This work was funded by a grant from the Economic and Social Research Council (grant

number: ES/K001884/1 to R.R.). We thank Kohinoor Darda for help constructing region of interest masks in our supplementary analyses. 


\section{References}

Aguirre GK (2007) Continuous carry-over designs for fMRI. Neuroimage 35:1480-1494 Available at: http://www.sciencedirect.com/science/article/pii/S1053811907001048 [Accessed July 29, 2015].

Bi Y, Wang X, Caramazza A (2016) Object Domain and Modality in the Ventral Visual Pathway. Trends Cogn Sci 20:282-290 Available at: http://www.sciencedirect.com/science/article/pii/S1364661316000437.

Borkenau P, Liebler A (1992) Trait Inferences: Sources of Validity at Zero Acquaintance. J Pers Soc Psychol 62:645-657.

Calvo-Merino B, Urgesi C, Orgs G, Aglioti SM, Haggard P (2010) Extrastriate body area underlies aesthetic evaluation of body stimuli. Exp Brain Res 204:447-456.

Cazzato V, Mele S, Urgesi C (2014) Gender differences in the neural underpinning of perceiving and appreciating the beauty of the body. Behav Brain Res 264:188-196 Available at: http://www.sciencedirect.com/science/article/pii/S0166432814000680.

Cazzato V, Mele S, Urgesi C (2016) Different contributions of visual and motor brain areas during liking judgments of same- and different-gender bodies. Brain Res 1646:98-108 Available at: http://www.sciencedirect.com/science/article/pii/S0006899316304097.

Cohen J (1992) A power primer. Psychol Bull 112:155-159.

Cross ES, Kirsch L, Ticini LF, Schütz-Bosbach S (2011) The Impact of Aesthetic Evaluation and Physical Ability on Dance Perception. Front Hum Neurosci 5.

de Gelder B (2006) Towards the neurobiology of emotional body language. Nat Rev Neurosci 7:242-249.

de Gelder B, van den Stock J, Meeren HKM, Sinke CBA, Kret ME, Tamietto M (2010) Standing up for the body. Recent progress in uncovering the networks involved in the perception of bodies and bodily expressions. Neurosci Biobehav Rev 34:513-527 Available at: http://dx.doi.org/10.1016/j.neubiorev.2009.10.008.

Dodell-Feder D, Koster-Hale J, Bedny M, Saxe RR (2011) fMRI item analysis in a theory of mind task. Neuroimage 55:705-712 Available at: http://www.ncbi.nlm.nih.gov/pubmed/21182967 [Accessed June 9, 2014].

Donnellan MB, Oswald FL, Baird BM, Lucas RE (2006) The mini-IPIP scales: tiny-yeteffective measures of the Big Five factors of personality. Psychol Assess 18:192-203.

Downing PE, Jiang Y, Shuman M, Kanwisher N (2001) A cortical area selective for visual processing of the human body. Science (80- ) 293:2470-2473 Available at: http://www.ncbi.nlm.nih.gov/pubmed/11577239 [Accessed June 3, 2014].

Downing PE, Peelen MV (2011) The role of occipitotemporal body-selective regions in person perception. Cogn Neurosci 2:186-226.

Downing PE, Peelen MV (2015) Body selectivity in occipitotemporal cortex: Causal evidence. Neuropsychologia in press:1-11 Available at: http://dx.doi.org/10.1016/j.neuropsychologia.2015.05.033.

Downing PE, Wiggett AJ, Peelen MV (2007) Functional magnetic resonance imaging investigation of overlapping lateral occipitotemporal activations using multi-voxel pattern analysis. J Neurosci 27:226-233 Available at: http://www.ncbi.nlm.nih.gov/pubmed/17202490 [Accessed June 15, 2014].

Eickhoff SB, Stephan KE, Mohlberg H, Grefkes C, Fink GR, Amunts K, Zilles K (2005) A new SPM toolbox for combining probabilistic cytoarchitectonic maps and functional imaging data. Neuroimage 25:1325-1335.

Eklund A, Nichols TE, Knutsson H (2016) Cluster failure: Why fMRI inferences for spatial extent have inflated false-positive rates. Proc Natl Acad Sci U S A 113:7900-7905.

Friston KJ (1994) Functional and Effective Connectivity in Neuroimaging: A Synthesis. Hum 
Brain Mapp 2:56-78.

Friston KJ, Buechel C, Fink GR, Morris J, Rolls E, Dolan RJ (1997) Psychophysiological and modulatory interactions in neuroimaging. Neuroimage 6:218-229 Available at: http://www.ncbi.nlm.nih.gov/pubmed/9344826.

Friston KJ, Price CJ (2001) Generative models, brain function and neuroimaging. Scand J Psychol 42:167-177.

Frith CD, Frith U (1999) Interacting Minds--A Biological Basis. Science (80- ) 286:16921695 Available at: http://www.sciencemag.org/cgi/doi/10.1126/science.286.5445.1692 [Accessed May 28, 2014].

Gitelman DR, Penny WD, Ashburner J, Friston KJ (2003) Modeling regional and psychophysiologic interactions in fMRI: the importance of hemodynamic deconvolution. Neuroimage 19:200-207 Available at: http://linkinghub.elsevier.com/retrieve/pii/S1053811903000582 [Accessed May 23, 2014].

Greven IM, Downing PE, Ramsey R (2016) Linking person perception to person knowledge in the human brain. Soc Cogn Affect Neurosci 11:641-651.

Greven IM, Ramsey R (2017a) Person perception involves functional integration between the extrastriate body area and temporal pole. Neuropsychologia.

Greven IM, Ramsey R (2017b) Neural network integration during the perception of in-group and out-group members. Neuropsychologia 106:225-235.

Harel A, Kravitz DJ, Baker CI (2014) Task context impacts visual object processing differentially across the cortex. Proc Natl Acad Sci 111:E962-E971 Available at: http://www.pnas.org/content/111/10/E962.abstract.

Ishai A (2008) Let's face it: It's a cortical network. Neuroimage 40:415-419.

Johnstone LT, Downing PE (2017) Dissecting the visual perception of body shape with the Garner selective attention paradigm paradigm. Vis cogn:1-17.

Josephs O, Henson RNA (1999) Event-related functional magnetic resonance imaging: modelling, inference and optimization. Philos Trans R Soc Lond B Biol Sci 354:12151228.

Klapper A, Ramsey R, Wigboldus DHJ, Cross ES (2014) The Control of Automatic Imitation Based on Bottom-Up and Top-Down Cues to Animacy: Insights from Brain and Behavior. J Cogn Neurosci 26:2503-2513.

Kramer RSS, Ward R (2010) Internal facial features are signals of personality and health. Q J Exp Psychol 63:2273-2287.

Kriegeskorte N, Mur M, Bandettino P (2008) Representational similarity analysis connecting the branches of systems neuroscience. Front Syst Neurosci 2:1-28 Available at: http://journal.frontiersin.org/article/10.3389/neuro.06.004.2008/abstract.

Lakens D (2013) Calculating and reporting effect sizes to facilitate cumulative science: a practical primer for t-tests and ANOVAs. Front Psychol 4:1-12.

Ma N, Baetens K, Vandekerckhove M, Kestemont J, Fias W, Van Overwalle F (2014) Traits are represented in the medial prefrontal cortex: An fMRI adaptation study. Soc Cogn Affect Neurosci 9:1185-1192.

Ma N, Vandekerckhove M, van Overwalle F, Seurinck R, Fias W (2011) Spontaneous and intentional trait inferences recruit a common mentalizing network to a different degree: spontaneous inferences activate only its core areas. Soc Neurosci 6:123-138 Available at: http://www.ncbi.nlm.nih.gov/pubmed/20661837 [Accessed June 9, 2014].

McLaren DG, Ries ML, Xu G, Johnson SC (2012) A generalized form of context-dependent psychophysiological interactions (gPPI): a comparison to standard approaches.

Neuroimage 61:1277-1286 Available at:

http://www.pubmedcentral.nih.gov/articlerender.fcgi?artid=3376181\&tool=pmcentrez\&r 
endertype $=$ abstract [Accessed June 12, 2014].

Mitchell JP (2009) Inferences about mental states. Philos Trans R Soc Lond B Biol Sci 364:1309-1316 Available at:

http://www.pubmedcentral.nih.gov/articlerender.fcgi?artid=2666715\&tool=pmcentrez\&r endertype=abstract [Accessed June 2, 2014].

Mitchell JP, Cloutier J, Banaji MR, Macrae CN (2006) Medial prefrontal dissociations during processing of trait diagnostic and nondiagnostic person information. Soc Cogn Affect Neurosci 1:49-55 Available at:

http://www.pubmedcentral.nih.gov/articlerender.fcgi?artid=2555403\&tool=pmcentrez\&r endertype $=$ abstract [Accessed July 8, 2014].

Mitchell JP, Heatherton TF, Macrae CN (2002) Distinct neural systems subserve person and object knowledge. Proc Natl Acad Sci U S A 99:15238-15243 Available at: http://www.pubmedcentral.nih.gov/articlerender.fcgi?artid=137574\&tool=pmcentrez\&re ndertype $=$ abstract .

Mitchell JP, Macrae CN, Banaji MR (2005) Forming impressions of people versus inanimate objects: social-cognitive processing in the medial prefrontal cortex. Neuroimage 26:251257 Available at: http://www.ncbi.nlm.nih.gov/pubmed/15862225 [Accessed June 16, 2014].

Musher-Eizenman D, Carels RA (2009) The impact of target weight and gender on perceptions of likeability, personality attributes, and functional impairment. Obes Facts 2:311-317.

Naumann LP, Vazire S, Rentfrow PJ, Gosling SD (2009) Personality judgments based on physical appearance. Personal Soc Psychol Bull 35:1661-1671 Available at: http://www.ncbi.nlm.nih.gov/pubmed/19762717 [Accessed May 31, 2014].

Norman KA, Polyn SM, Detre GJ, Haxby JV (2006) Beyond mind-reading: multi-voxel pattern analysis of fMRI data. Trends Cogn Sci 10:424-430 Available at: http://www.ncbi.nlm.nih.gov/pubmed/16899397 [Accessed July 9, 2014].

Olson IR, McCoy D, Klobusicky E, Ross LA (2013) Social cognition and the anterior temporal lobes: a review and theoretical framework. Soc Cogn Affect Neurosci 8:123133 Available at:

http://www.pubmedcentral.nih.gov/articlerender.fcgi?artid=3575728\&tool=pmcentrez\&r endertype=abstract [Accessed May 26, 2014].

Peelen M V, Downing PE (2017) Category selectivity in human visual cortex: Beyond visual object recognition. Neuropsychologia Available at: http://www.sciencedirect.com/science/article/pii/S0028393217301215.

Puhl R, Brownell KD (2001) Bias, Discrimination, and Obesity. Obes Res 9:788-805 Available at: http://doi.wiley.com/10.1038/oby.2001.108.

Puhl RM, Heuer CA (2009) The stigma of obesity: a review and update. Obesity 17:941-964.

Quadflieg S, Flannigan N, Waiter GD, Rossion B, Wig GS, Turk DJ, Macrae CN (2011) Stereotype-based modulation of person perception. Neuroimage 57:549-557.

Quadflieg S, Rossion B (2011) When perception and attention collide: Neural processing in EBA and FBA. Cogn Neurosci 2:209-210 Available at: http://dx.doi.org/10.1080/17588928.2011.604722.

Ramsey R, van Schie HT, Cross ES (2011) No two are the same: Body shape is part of identifying others. Cogn Neurosci 2:207-208 Available at: http://dx.doi.org/10.1080/17588928.2011.604721.

Saxe RR, Kanwisher N (2003) People thinking about thinking peopleThe role of the temporoparietal junction in "theory of mind." Neuroimage 19:1835-1842 Available at: http://linkinghub.elsevier.com/retrieve/pii/S1053811903002301 [Accessed May 24, 2014]. 
Sell A, Cosmides L, Tooby J, Sznycer D, von Rueden C, Gurven M (2009) Human adaptations for the visual assessment of strength and fighting ability from the body and face. Proc R Soc London B 276:575-584.

Sporns O (2013) The human connectome: Origins and challenges. Neuroimage 80:53-61 Available at: http://dx.doi.org/10.1016/j.neuroimage.2013.03.023.

Sporns O, Tononi G, Kötter R (2005) The human connectome: A structural description of the human brain. PLoS Comput Biol 1:0245-0251.

Spunt RP, Lieberman MD (2012) Dissociating Modality-Specific and Supramodal Neural Systems for Action Understanding. J Neurosci 32:3575-3583.

Stanislaw H, Todorov N (1999) Calculation of signal detection theory measures. Behav Res Methods, Instruments, Comput 31:137-149.

Stulp G, Buunk AP, Verhulst S, Pollet T V (2015) Human Height Is Positively Related to Interpersonal Dominance in Dyadic Interactions. PLoS One 10:1-18 Available at: http://dx.plos.org/10.1371/journal.pone.0117860.

Sturman D, Stephen ID, Mond J, Stevenson RJ, Brooks KR (2017) Independent Aftereffects of Fat and Muscle: Implications for neural encoding, body space representation, and body image disturbance. Nat Sci Reports 7:1-8 Available at: http://dx.doi.org/10.1038/srep40392.

Todorov A, Mende-Siedlecki P, Dotsch R (2013) Social judgments from faces. Curr Opin Neurobiol 23:373-380 Available at: http://dx.doi.org/10.1016/j.conb.2012.12.010.

Uleman JS, Adil Saribay S, Gonzalez CM (2008) Spontaneous inferences, implicit impressions, and implicit theories. Annu Rev Psychol 59:329-360 Available at: http://www.ncbi.nlm.nih.gov/pubmed/17854284 [Accessed May 30, 2014].

van Overwalle F (2009) Social cognition and the brain: a meta-analysis. Hum Brain Mapp 30:829-858 Available at: http://www.scopus.com/inward/record.url?eid=2-s2.060849090562\&partnerID=tZOtx3y1.

Visser M, Jefferies E, Ralph MAL (2009) Semantic Processing in the Anterior Temporal Lobes: A Meta-analysis of the Functional Neuroimaging Literature. J Cogn Neurosci 22:1083-1094.

Wager TD, Nichols TE (2003) Optimization of experimental design in fMRI: a general framework using a genetic algorithm. Neuroimage 18:293-309 Available at: http://linkinghub.elsevier.com/retrieve/pii/S1053811902000460 [Accessed May 29, 2014].

Wang Y, Collins JA, Koski J, Nugiel T, Metoki A, Olson IR (2017) Dynamic neural architecture for social knowledge retrieval. Proc Natl Acad Sci 114:E3305-E3314 Available at: http://www.pnas.org/content/114/16/E3305.abstract.

Ware JEJR, Kosinski M, Keller SD (1996) A 12-Item Short-Form Health Survey: Construction of Scales and Preliminary Tests of Reliability and Validity. Med Care 34:220-233 Available at: http://journals.lww.com/lwwmedicalcare/Fulltext/1996/03000/A_12_Item_Short_Form_Health_Survey_Constructio n.3.aspx. 
Table 1. Results from the univariate analysis of the second fMRI experiment for 1) the Muscular $>$ Slim and 2) the Obese $>$ Slim contrasts are presented a) masked by the bodylocaliser (focussing on EBA and FBA), and b) masked by the ToM-localiser.

Region Number Cluster $P$ Peak Montreal

$$
\text { of voxels } \quad F W E \quad T \quad \text { Neurological }
$$

Institute coordinates

$\begin{array}{lll}\mathrm{x} & \mathrm{y}\end{array}$

1) Muscular > Slim

1.a) Masked by body-localiser (EBA and FBA)

\begin{tabular}{lllllll}
\hline Left inferior occipital gyrus (EBA) & 46 & .022 & 4.79 & -42 & -79 & -2 \\
Right inferior occipital gyrus (EBA) & 95 & .006 & 4.47 & 42 & -76 & -8 \\
extending into fusiform gyrus (FBA) & & & & & & \\
\end{tabular}

1.b) Masked by ToM-localiser

No suprathreshold clusters

2) Obese > Slim

2.a) Masked by body-localiser (EBA and FBA)

No suprathreshold clusters

\section{2.b) Masked by ToM-localiser}

\begin{tabular}{lcccccc}
\hline Right temporal pole & 13 & .20 & 4.64 & 42 & 2 & -38 \\
Left temporal pole & 6 & .29 & 4.06 & -45 & 2 & -38 \\
Medial prefrontal cortex & 6 & .29 & 3.79 & -9 & 53 & 10 \\
Medial prefrontal cortex & 8 & .26 & 3.79 & -6 & 44 & 28
\end{tabular}

Note: Regions surviving a voxel-level threshold of $\mathrm{p}<.001$ and 5 voxels are reported. Areas in bold survive FWE cluster correction for multiple comparisons. Subclusters at least $4 \mathrm{~mm}$ from the main peak are listed. 
Table 2. Results from the PPI analysis of the second fMRI experiment for the Obese $>$ Slim contrast are presented a) masked by the body-localiser (focussing on EBA and FBA), and b) masked by the ToM-localiser.

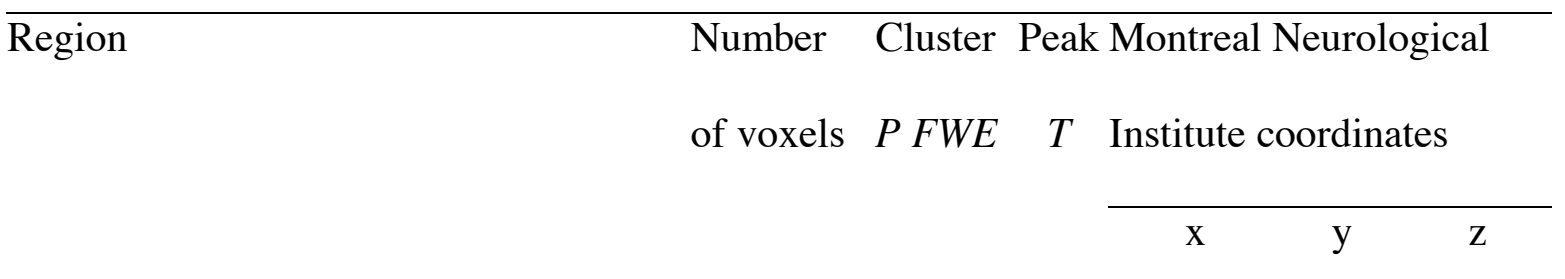

a) Masked by body-localiser (EBA and FBA)

Seed regions: anterior mPFC, bilateral temporal poles, bilateral TPJ, and Precuneus

No suprathreshold clusters

b) Masked by ToM-localiser

Seed regions: right $\mathrm{EBA}$

\begin{tabular}{lllllll}
\hline Right temporal pole & 5 & .32 & 3.88 & 54 & 8 & -23
\end{tabular}

Seed region: right $\mathrm{FBA}$

No suprathreshold clusters 


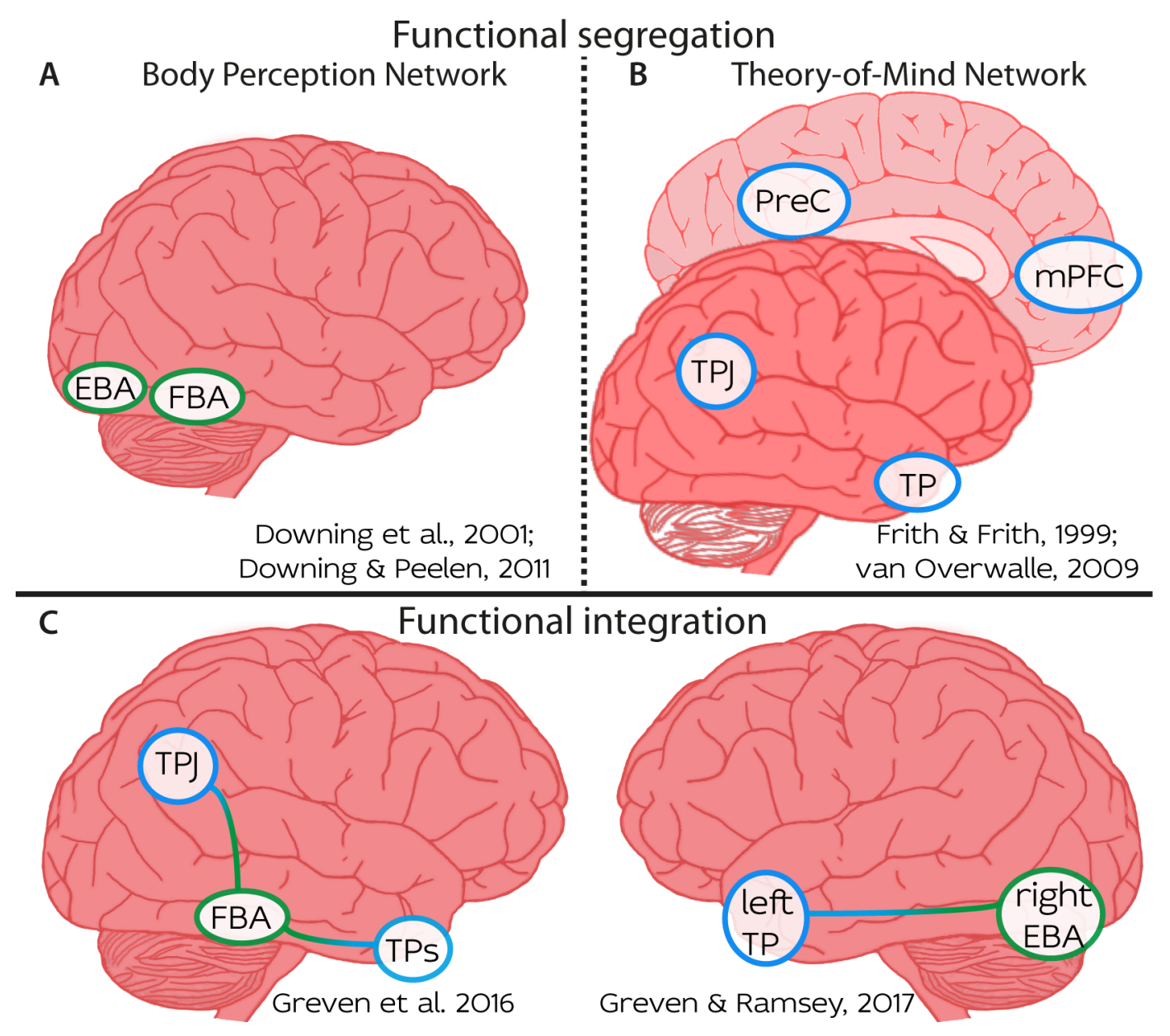

Figure 1. Neural networks supporting A) body perception, and B) Theory-of-Mind (ToM). C) Recent studies using functional connectivity analyses have shown that body and ToM networks also interact during social perception tasks that require integration of perceptual and inferential information about other people. 


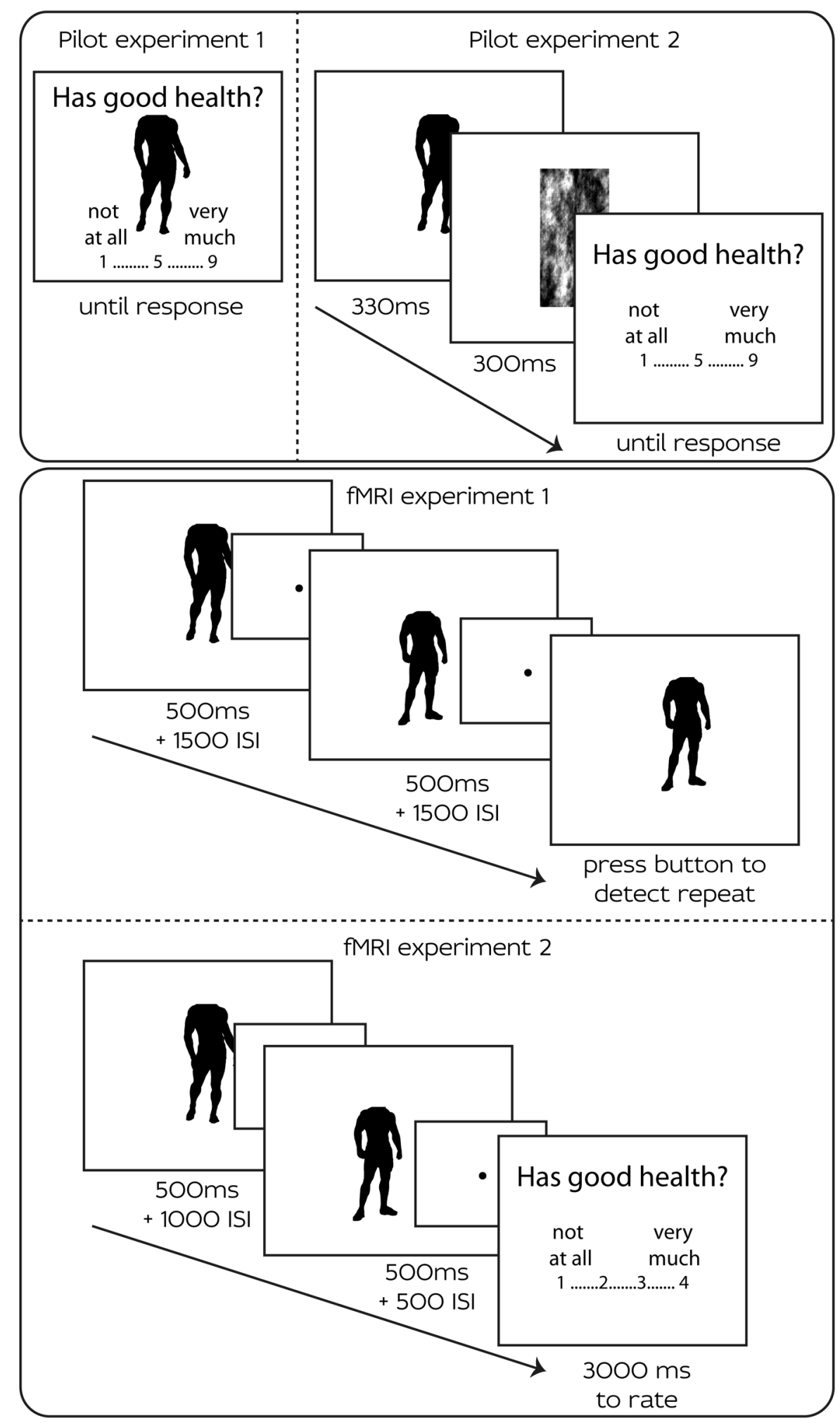

Figure 2. Methods for both pilot experiments and the fMRI experiment. Pilot experiment 1:

Each body remained on screen until the participant had rated it on the statement displayed above the body. Pilot experiment 2: each body was displayed for $330 \mathrm{~ms}$ after which it was backward masked for $300 \mathrm{~ms}$. After this the rating statement would appear on screen and 
remain there until the participant had provided the rating. fMRI experiment: to allow for spontaneous trait inferences, participants were not explicitly told to form an opinion of the bodies they saw, but instead performed a 1-back task where they had to detect a repeat. 


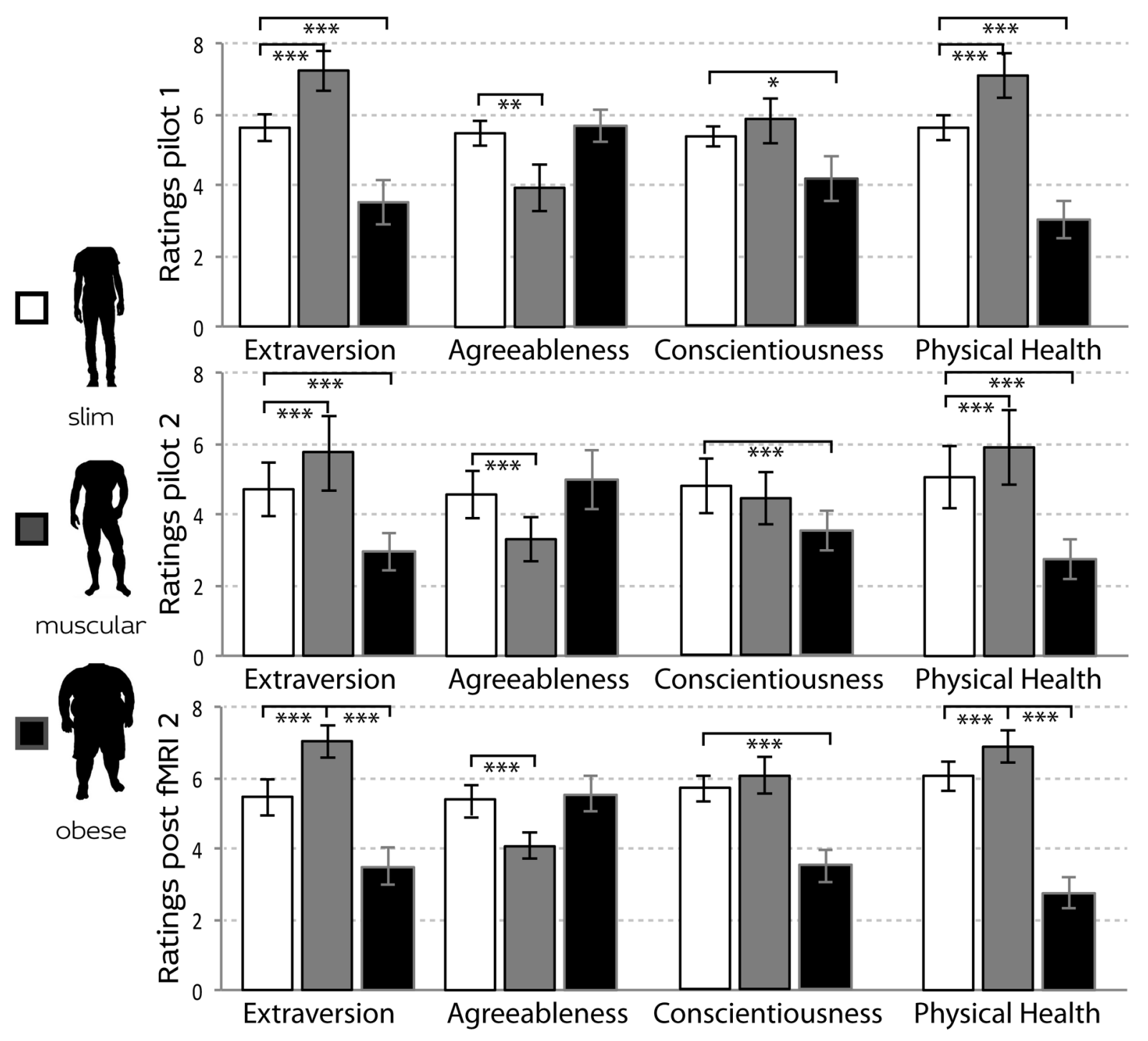

Figure 3. Ratings from pilot experiment 1 and 2 and post-scanning fMRI 2. Participants rated muscular bodies as more extraverted and healthy, but less agreeable in comparison to slim bodies. Obese bodies were rated as less extraverted, conscientious, and healthy in comparison to slim bodies. $*: p<.05, * *: p<.01, * * *: p<.001$. Error bars show $95 \%$ confidence intervals 


\section{A Design matrix (one for each run)}
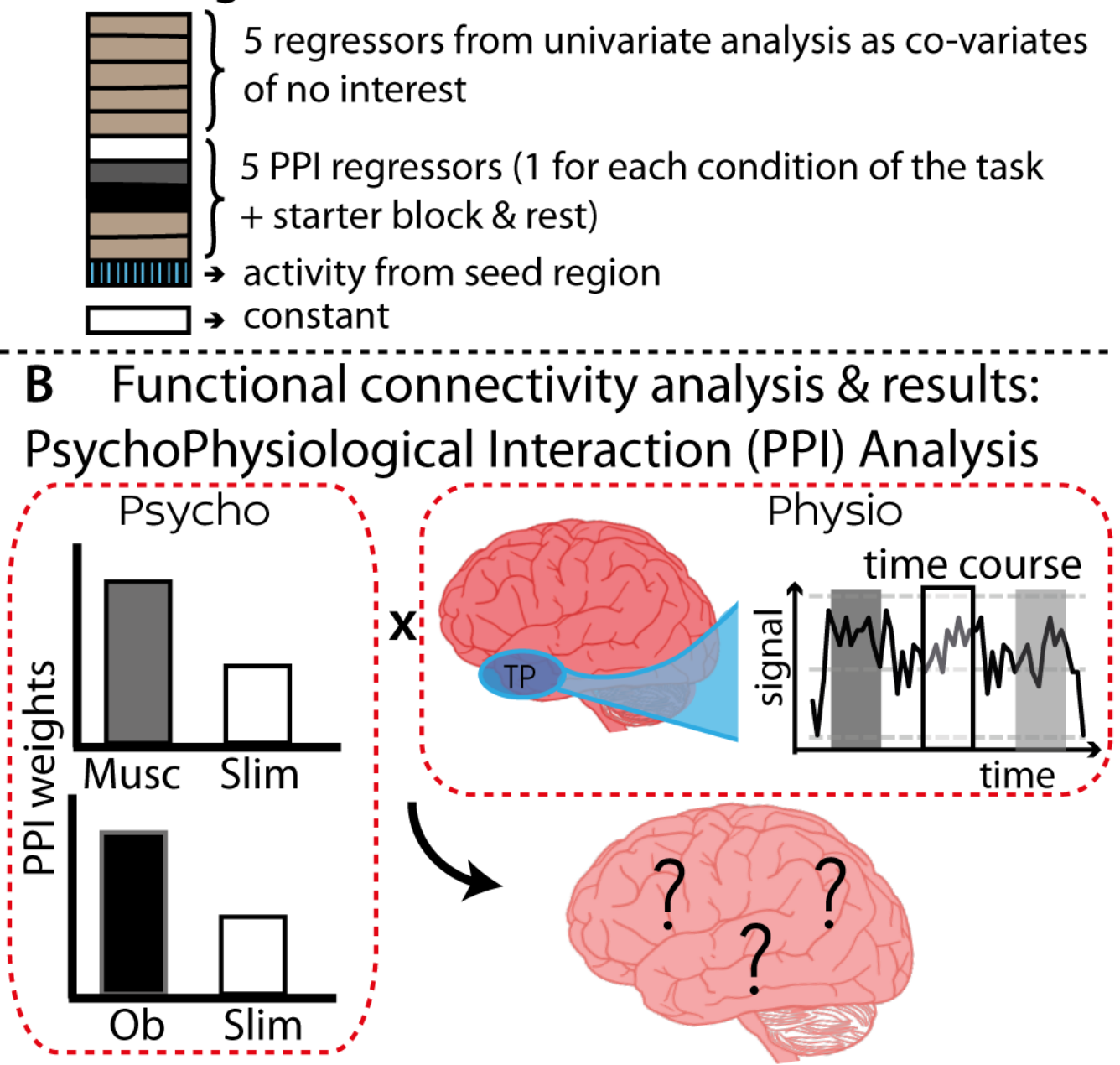

Figure 4. PsychoPhysiological Interactions (PPI) matrix and results. A) An illustration of the design matrix (this was the same for each run), that was created for each participant. B) The “psychological” (task) and "physiological" (time course from seed region) inputs for the PPI analysis. 


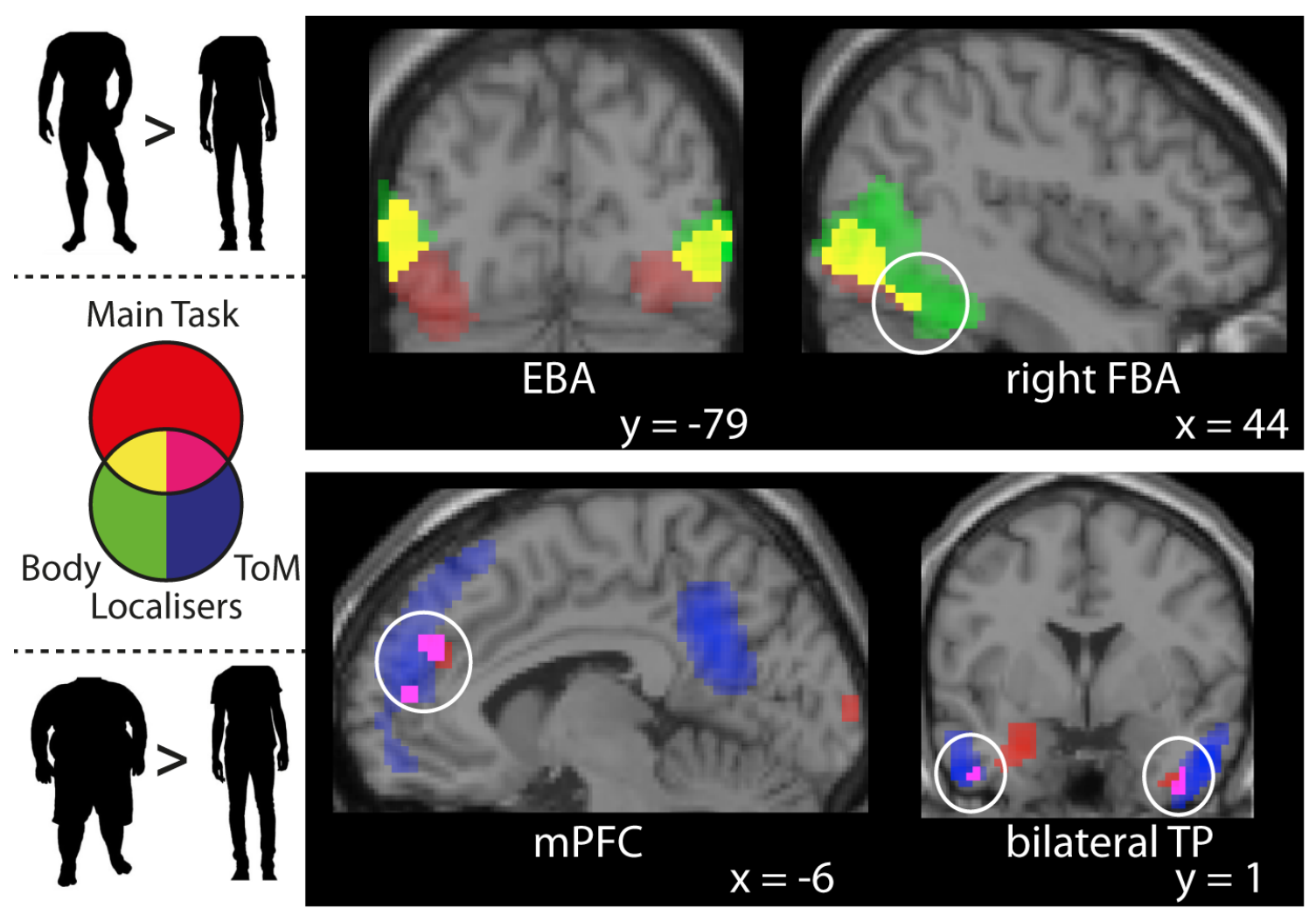

Figure 5. Results from the univariate analyses from Experiment 2 (shown in red). The contrast Muscular $>$ Slim revealed clusters of activity within bilateral extrastriate body area (EBA) and right fusiform body area (FBA) as identified with the body-localiser (Bodies > Cars: green, overlap in yellow). The contrast Obese $>$ Slim revealed clusters of activity within bilateral temporal poles (TP) and medial prefrontal cortex (mPFC) as identified by the ToMlocaliser (False Beliefs > False Photographs: blue, overlap in pink). 


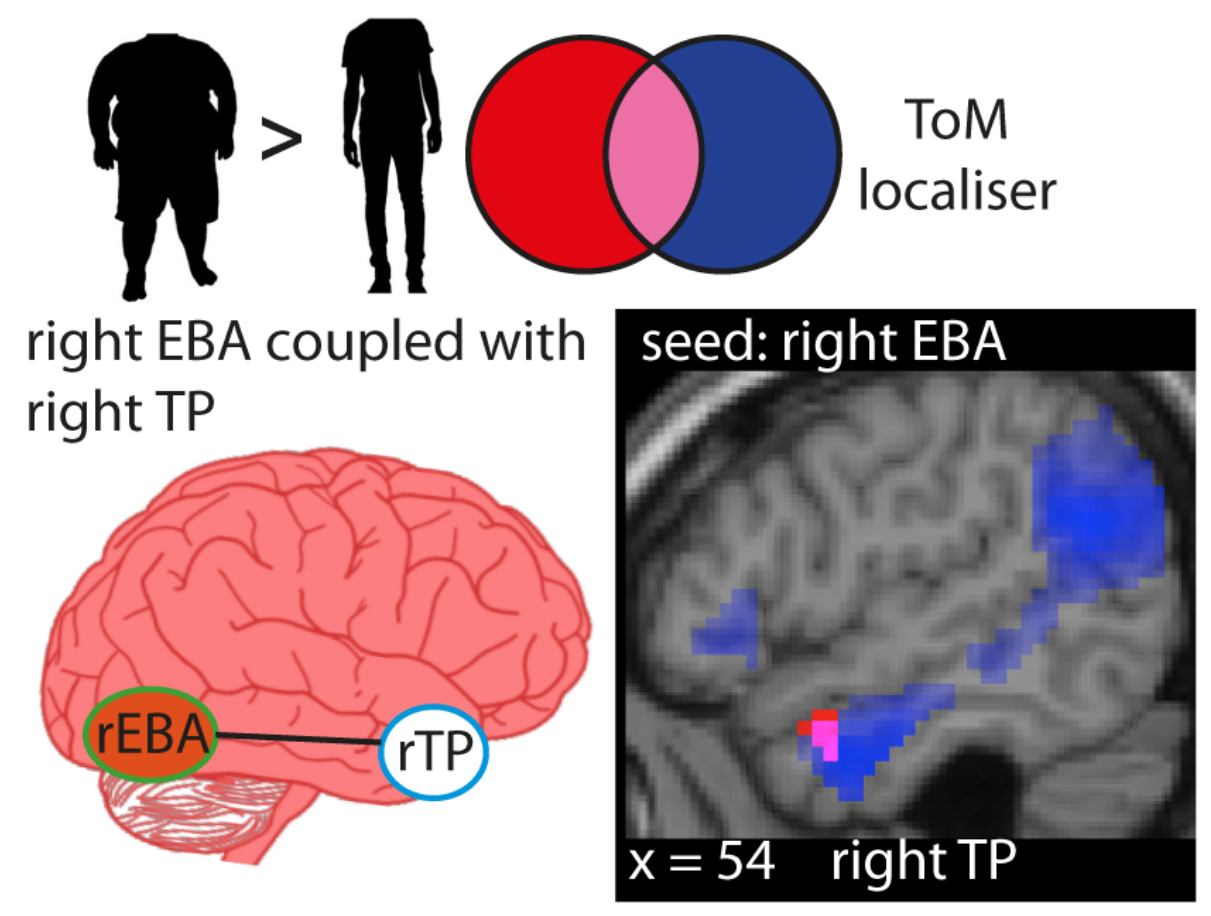

Figure 6. Results from the PsychoPhysiological Interaction (PPI) analyses from Experiment

2. Seed regions were identified using the independent localisers. PPI analyses were performed using each region ( 2 body-selective and 6 ToM regions) as a separate seed region. Clusters emerging from these analyses reveal the strength of correlation over time between activity in that cluster and that in the seed region as a function of the task. Here, when using right extrastriate body area (EBA) as a seed region, the contrast Obese $>$ Slim revealed stronger functional coupling with right temporal pole (TP). This area overlapped with the ToMlocaliser (shown in blue; overlap shown in pink). 
Supplementary Table 1. Behavioural results from pilot experiments and from the post-scanning behavioural data in the second fMRI

experiment.

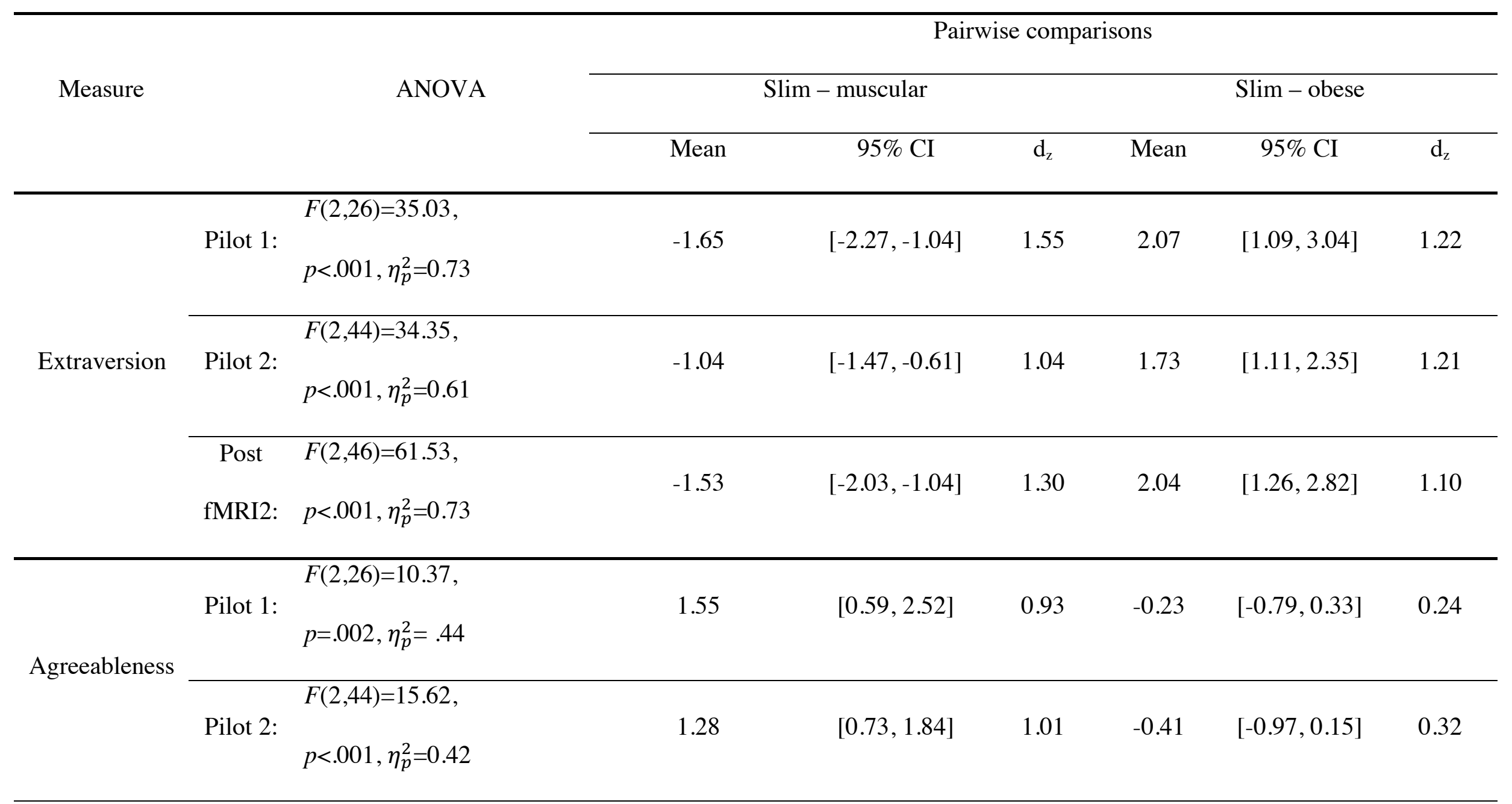




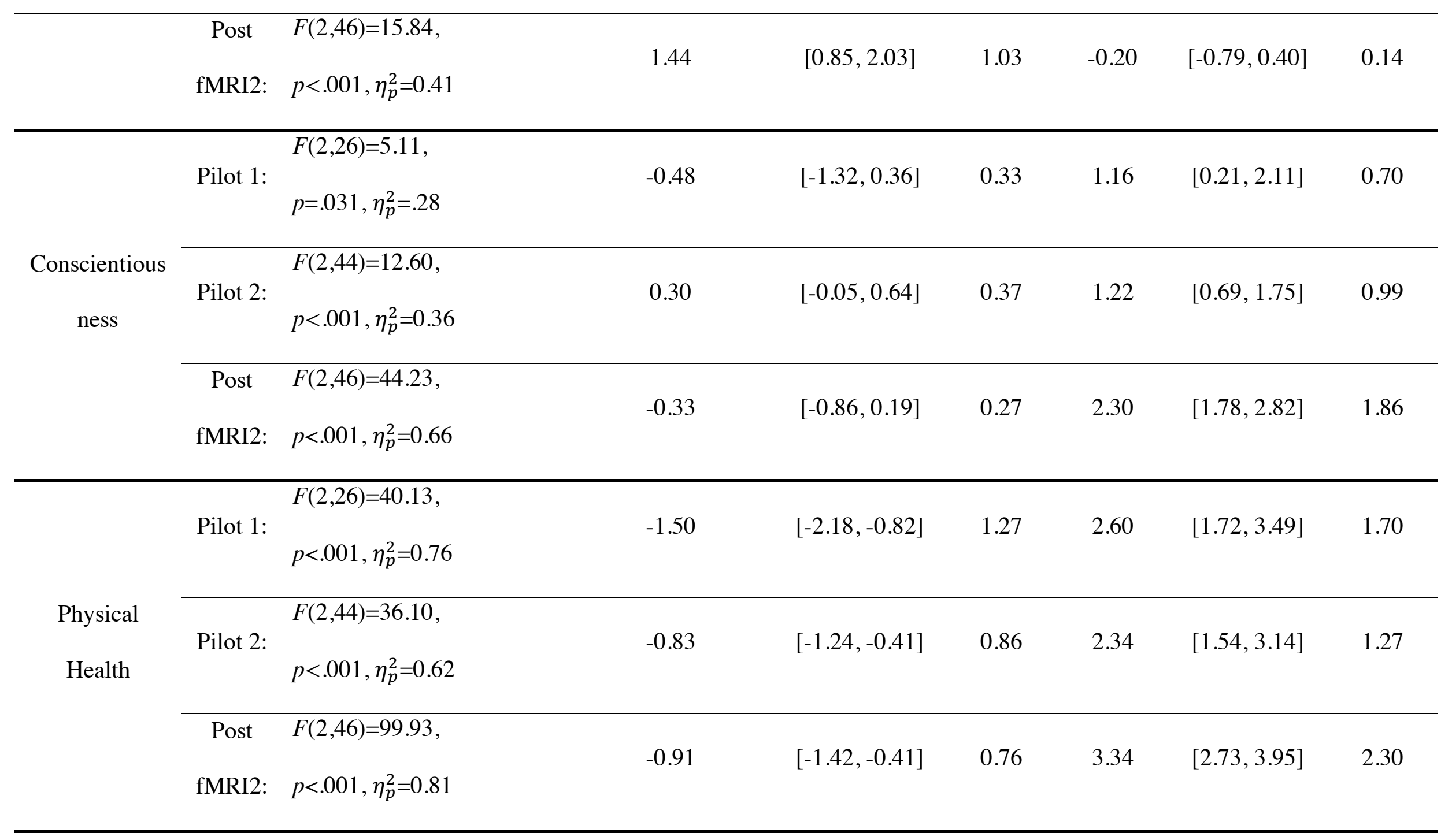


Supplementary Table 2. Details for PPI analyses with seed regions taken from the body- and Theory-of-Mind (ToM) localisers for fMRI experiment 1 .

\begin{tabular}{|c|c|c|c|c|c|c|c|}
\hline & & \multicolumn{2}{|c|}{ Body-localiser } & \multicolumn{4}{|c|}{ ToM-localiser } \\
\hline & & EBA & FBA & TPJ & $\mathrm{TP}$ & Precuneus & $\mathrm{mPFC}$ \\
\hline \multirow{2}{*}{$\begin{array}{l}\text { Number of } \\
\text { subjects } \\
\text { (total 26) }\end{array}$} & Left & - & - & $21(25)$ & $15(25)$ & \multirow[b]{2}{*}{$22(23)$} & \multirow[b]{2}{*}{$22(26)$} \\
\hline & Right & $26(26)$ & $23(23)$ & $22(24)$ & $20(26)$ & & \\
\hline \multirow{2}{*}{$\begin{array}{l}\text { Mean MNI } \\
\text { coordinate }\end{array}$} & Left & - & - & $-54,-58,16$ & $-51,5,-35$ & \multirow{2}{*}{$0,-64,28$} & \multirow{2}{*}{$-15,47,34$} \\
\hline & Right & $51,-76,-5$ & $48,-40,-23$ & $54,-67,22$ & $57,2,-32$ & & \\
\hline \multirow{3}{*}{ SD coordinate } & $X$ & $\mathrm{R}=4.13$ & $\mathrm{R}=4.01$ & $\begin{array}{l}L=6.56 \\
R=6.53\end{array}$ & $\begin{array}{l}\mathrm{L}=5.63 \\
\mathrm{R}=4.20\end{array}$ & 7.38 & 9.31 \\
\hline & $\mathrm{Y}$ & $\mathrm{R}=4.49$ & $\mathrm{R}=9.12$ & $\begin{array}{l}\mathrm{L}=6.42 \\
\mathrm{R}=6.50\end{array}$ & $\begin{array}{l}\mathrm{L}=5.98 \\
\mathrm{R}=7.43\end{array}$ & 6.22 & 6.84 \\
\hline & $\mathrm{Z}$ & $\mathrm{R}=4.24$ & $\mathrm{R}=5.70$ & $\begin{array}{l}L=5.58 \\
R=6.06\end{array}$ & $\begin{array}{l}\mathrm{L}=8.32 \\
\mathrm{R}=6.09\end{array}$ & 7.98 & 15.32 \\
\hline
\end{tabular}

Note: Number of subjects are reported at two thresholds: $\mathrm{p}<.001$ and $(\mathrm{p}<.01)$.

MNI = Montreal Neurological Institute. 
Supplementary Table 3. Details for PPI analyses with seed regions taken from the body- and Theory-of-Mind (ToM) localisers for fMRI experiment 2 .

\begin{tabular}{|c|c|c|c|c|c|c|c|}
\hline & & \multicolumn{2}{|c|}{ Body-localiser } & \multicolumn{4}{|c|}{ ToM-localiser } \\
\hline & & EBA & FBA & TPJ & $\mathrm{TP}$ & Precuneus & $\mathrm{mPFC}$ \\
\hline \multirow{2}{*}{$\begin{array}{c}\text { Number of } \\
\text { subjects } \\
\text { (total: Body = } \\
\text { 25; ToM = 24) }\end{array}$} & Left & - & - & $21(22)$ & $15(23)$ & \multirow[b]{2}{*}{$16(24)$} & \multirow[b]{2}{*}{$18(24)$} \\
\hline & Right & $25(25)$ & $18(20)$ & $22(23)$ & $18(23)$ & & \\
\hline \multirow{2}{*}{$\begin{array}{c}\text { Mean } \\
\text { coordinate }\end{array}$} & Left & - & - & $-54,-58,16$ & $-51,2,-35$ & \multirow{2}{*}{$0,-58,28$} & \multirow{2}{*}{$15,56,16$} \\
\hline & Right & $48,-76,1$ & $45,-43,-23$ & $54,-67,22$ & $51,5,-29$ & & \\
\hline \multirow{3}{*}{ SD coordinate } & $X$ & $\mathrm{R}=3.64$ & $\mathrm{R}=3.83$ & $\begin{array}{l}L=6.56 \\
R=6.53\end{array}$ & $\begin{array}{l}\mathrm{L}=5.60 \\
\mathrm{R}=5.66\end{array}$ & 6.41 & 10.98 \\
\hline & $\mathrm{Y}$ & $\mathrm{R}=4.41$ & $R=5.63$ & $\begin{array}{l}\mathrm{L}=6.42 \\
\mathrm{R}=6.50\end{array}$ & $\begin{array}{l}\mathrm{L}=4.61 \\
\mathrm{R}=4.50\end{array}$ & 5.11 & 6.86 \\
\hline & $\mathrm{Z}$ & $\mathrm{R}=7.32$ & $\mathrm{R}=4.91$ & $\begin{array}{l}\mathrm{L}=5.58 \\
\mathrm{R}=6.06\end{array}$ & $\begin{array}{l}\mathrm{L}=6.67 \\
\mathrm{R}=6.17\end{array}$ & 7.51 & 9.45 \\
\hline
\end{tabular}

Note: Number of subjects are reported at two thresholds: $p<.001$ and $(p<.01)$.

MNI = Montreal Neurological Institute. 
Supplementary Table 4. Functional region of interest data for Experiment 1.

\begin{tabular}{|c|c|c|c|c|c|c|}
\hline Region & $\begin{array}{c}\text { ROI size } \\
\text { (voxels) }\end{array}$ & $\begin{array}{c}\text { Average } \\
\text { localiser } \\
\text { mask size } \\
\text { (voxels) }\end{array}$ & $\begin{array}{c}\text { Inter- } \\
\text { subject } \\
\text { overlap } \\
(\%)\end{array}$ & $\begin{array}{l}\text { Percent } \\
\text { signal } \\
\text { change } \\
(\text { SEM) }\end{array}$ & $\mathbf{t}$ & $\mathbf{p}(\mathbf{f d r})$ \\
\hline \multicolumn{7}{|l|}{ Slim > Fixation } \\
\hline \multicolumn{7}{|l|}{ Body localiser } \\
\hline Right EBA & 151 & 98 & 100 & $3.15(0.4)$ & 7.87 & $<0.001$ \\
\hline Right FBA & 159 & 26 & 88 & $1.7(0.22)$ & 7.87 & $<0.001$ \\
\hline \multicolumn{7}{|l|}{ ToM localiser } \\
\hline Right TPJ & 993 & 265 & 88 & $-0.67(0.24)$ & -2.86 & 0.999 \\
\hline Left TPJ & 985 & 166 & 85 & $-0.89(0.24)$ & -3.64 & 0.999 \\
\hline Right TP & 169 & 27 & 62 & $-0.51(0.18)$ & -2.89 & 0.999 \\
\hline Left TP & 160 & 21 & 46 & $-0.16(0.26)$ & -0.6 & 0.999 \\
\hline precuneus & 1159 & 189 & 81 & $-1.38(0.44)$ & -3.12 & 0.999 \\
\hline Dorsal mPFC & 609 & 48 & 58 & $-0.48(0.37)$ & -1.32 & 0.999 \\
\hline Middle mPFC & 493 & 31 & 54 & $-0.63(0.44)$ & -1.45 & 0.999 \\
\hline Ventral mPFC & - & - & - & - & - & - \\
\hline \multicolumn{7}{|c|}{ Muscular $>$ Fixation } \\
\hline \multicolumn{7}{|l|}{ Body localiser } \\
\hline Right EBA & 151 & 98 & 100 & $3.42(0.4)$ & 8.48 & $<0.001$ \\
\hline Right FBA & 159 & 26 & 88 & $2.15(0.25)$ & 8.73 & $<0.001$ \\
\hline \multicolumn{7}{|l|}{ ToM localiser } \\
\hline Right TPJ & 993 & 265 & 88 & $-0.99(0.17)$ & -5.75 & 1 \\
\hline Left TPJ & 985 & 166 & 85 & $-1.1(0.25)$ & -4.48 & 1 \\
\hline Right TP & 169 & 27 & 62 & $-0.81(0.18)$ & -4.55 & 1 \\
\hline Left TP & 160 & 21 & 46 & $-0.15(0.24)$ & -0.65 & 1 \\
\hline precuneus & 1159 & 189 & 81 & $-1.91(0.35)$ & -5.43 & 1 \\
\hline Dorsal mPFC & 609 & 48 & 58 & $-0.53(0.29)$ & -1.84 & 1 \\
\hline Middle mPFC & 493 & 31 & 54 & $-0.78(0.36)$ & -2.18 & 1 \\
\hline Ventral mPFC & - & - & - & - & - & - \\
\hline \multicolumn{7}{|c|}{ Obese $>$ Fixation } \\
\hline \multicolumn{7}{|l|}{ Body localiser } \\
\hline Right EBA & 151 & 98 & 100 & $2.91(0.37)$ & 7.83 & $<0.001$ \\
\hline Right FBA & 159 & 26 & 88 & $1.71(0.21)$ & 8.26 & $<0.001$ \\
\hline \multicolumn{7}{|l|}{ ToM localiser } \\
\hline Right TPJ & 993 & 265 & 88 & $-1.33(0.22)$ & -5.97 & 1 \\
\hline Left TPJ & 985 & 166 & 85 & $-1.42(0.23)$ & -6.05 & 1 \\
\hline Right TP & 169 & 27 & 62 & $-0.96(0.15)$ & -6.52 & 1 \\
\hline Left TP & 160 & 21 & 46 & $-0.42(0.24)$ & -1.78 & 1 \\
\hline precuneus & 1159 & 189 & 81 & $-2.25(0.41)$ & -5.53 & 1 \\
\hline Dorsal mPFC & 609 & 48 & 58 & $-0.81(0.37)$ & -2.21 & 1 \\
\hline
\end{tabular}




\begin{tabular}{|l|c|c|c|c|c|c|}
\hline Middle mPFC & 493 & 31 & 54 & $-1.13(0.36)$ & -3.17 & 1 \\
\hline Ventral mPFC & - & - & - & - & - & - \\
\hline
\end{tabular}

Abbreviations: $\mathrm{ROI}=$ Region of interest $\mathrm{fdr}=$ false discovery rate EBA = extrastriate body area; $\mathrm{FBA}=$ right fusiform body area; $\mathrm{TPJ}=$ temporoparietal junction; $\mathrm{mPFC}=$ medial prefrontal cortex; ant. Temp. $=$ anterior temporal.

Note: 'ROI size' is the total number of voxels in each ROI based on data from a body perception localiser or a theory-of-mind localiser. 'Average localiser mask size' is the number of voxels that overlap in more than $25 \%$ of participants within each ROI. Right EBA, for example, consists of a 151 voxel ROI, with 98 voxels showing overlap in $100 \%$ of participants. Analyses were performed on the subset of voxels in each ROI that show overlap in more than $25 \%$ of participants. Responses for the ToM localiser in ventral mPFC did not overlap in more than $25 \%$ of participants and therefore no data are reported. 
Supplementary Table 5. Functional region of interest data for Experiment 2.

\begin{tabular}{|c|c|c|c|c|c|c|}
\hline Region & $\begin{array}{c}\text { ROI size } \\
\text { (voxels) }\end{array}$ & $\begin{array}{c}\text { Average } \\
\text { localiser } \\
\text { mask size } \\
\text { (voxels) }\end{array}$ & $\begin{array}{c}\text { Inter- } \\
\text { subject } \\
\text { overlap } \\
(\%)\end{array}$ & $\begin{array}{l}\text { Percent } \\
\text { signal } \\
\text { change } \\
\text { (SEM) }\end{array}$ & $\mathbf{t}$ & $\mathbf{p}(\mathbf{f d r})$ \\
\hline \multicolumn{7}{|l|}{ Slim > Fixation } \\
\hline \multicolumn{7}{|l|}{ Body localiser } \\
\hline Right EBA & 160 & 61 & 100 & $4.98(0.42)$ & 11.72 & $<0.001$ \\
\hline Right FBA & 153 & 14 & 64 & $1.64(0.21)$ & 7.69 & $<0.001$ \\
\hline \multicolumn{7}{|l|}{ ToM localiser } \\
\hline Right TPJ & 993 & 295 & 92 & $-0.70(0.26)$ & -2.67 & 0.993 \\
\hline Left TPJ & 985 & 214 & 88 & $-0.21(0.26)$ & -0.84 & 0.993 \\
\hline Right TP & 151 & 27 & 71 & $-0.36(0.28)$ & -1.25 & 0.993 \\
\hline Left TP & 169 & 13 & 63 & $0.26(0.34)$ & 0.76 & 0.993 \\
\hline precuneus & 1159 & 136 & 67 & $-0.98(0.41)$ & -2.38 & 0.993 \\
\hline Dorsal mPFC & 609 & 70 & 58 & $-0.05(0.27)$ & -0.18 & 0.993 \\
\hline Middle mPFC & 493 & 50 & 54 & $-0.57(0.32)$ & -1.76 & 0.993 \\
\hline Ventral mPFC & 391 & 18 & 46 & $-0.43(0.68)$ & -0.63 & 0.993 \\
\hline \multicolumn{7}{|c|}{ Muscular $>$ Fixation } \\
\hline \multicolumn{7}{|l|}{ Body localiser } \\
\hline Right EBA & 160 & 61 & 100 & $5.58(0.43)$ & 13.13 & $<0.001$ \\
\hline Right FBA & 153 & 14 & 64 & $1.95(0.28)$ & 7.01 & $<0.001$ \\
\hline \multicolumn{7}{|l|}{ ToM localiser } \\
\hline Right TPJ & 993 & 295 & 92 & $-0.74(0.19)$ & -3.98 & 1 \\
\hline Left TPJ & 985 & 214 & 88 & $-0.22(0.14)$ & -1.6 & 1 \\
\hline Right TP & 151 & 27 & 71 & $-0.29(0.15)$ & -1.88 & 1 \\
\hline Left TP & 169 & 13 & 63 & $0.46(0.12)$ & 4.29 & 0.006 \\
\hline precuneus & 1159 & 136 & 67 & $-1.23(0.27)$ & -4.55 & 1 \\
\hline Dorsal mPFC & 609 & 70 & 58 & $-0.12(0.2)$ & -0.61 & 1 \\
\hline Middle mPFC & 493 & 50 & 54 & $-0.81(0.28)$ & -2.94 & 1 \\
\hline Ventral mPFC & 391 & 18 & 46 & $-1.37(0.4)$ & -3.43 & 1 \\
\hline \multicolumn{7}{|c|}{ Obese $>$ Fixation } \\
\hline \multicolumn{7}{|l|}{ Body localiser } \\
\hline Right EBA & 160 & 61 & 100 & $4.86(0.46)$ & 10.52 & $<0.001$ \\
\hline Right FBA & 153 & 14 & 64 & $1.45(0.31)$ & 4.71 & $<0.001$ \\
\hline \multicolumn{7}{|l|}{ ToM localiser } \\
\hline Right TPJ & 993 & 295 & 92 & $-0.63(0.26)$ & -2.46 & 0.992 \\
\hline Left TPJ & 985 & 214 & 88 & $-0.02(0.24)$ & -0.08 & 0.992 \\
\hline Right TP & 151 & 27 & 71 & $-0.16(0.23)$ & -0.69 & 0.992 \\
\hline Left TP & 169 & 13 & 63 & $0.76(0.26)$ & 2.93 & 0.063 \\
\hline precuneus & 1159 & 136 & 67 & $-0.9(0.32)$ & -2.76 & 0.992 \\
\hline Dorsal mPFC & 609 & 70 & 58 & $0.26(0.29)$ & 0.88 & 0.893 \\
\hline
\end{tabular}




\begin{tabular}{|l|l|l|l|l|l|l|}
\hline Middle mPFC & 493 & 50 & 54 & $-0.54(0.31)$ & -1.74 & 0.992 \\
\hline Ventral mPFC & 391 & 18 & 46 & $-1.01(0.79)$ & -1.28 & 0.992 \\
\hline
\end{tabular}

Abbreviations as Supplementary Table 4. 
Supplementary Figure 1. Percent signal change data in functional regions of interest for

Experiment 1.

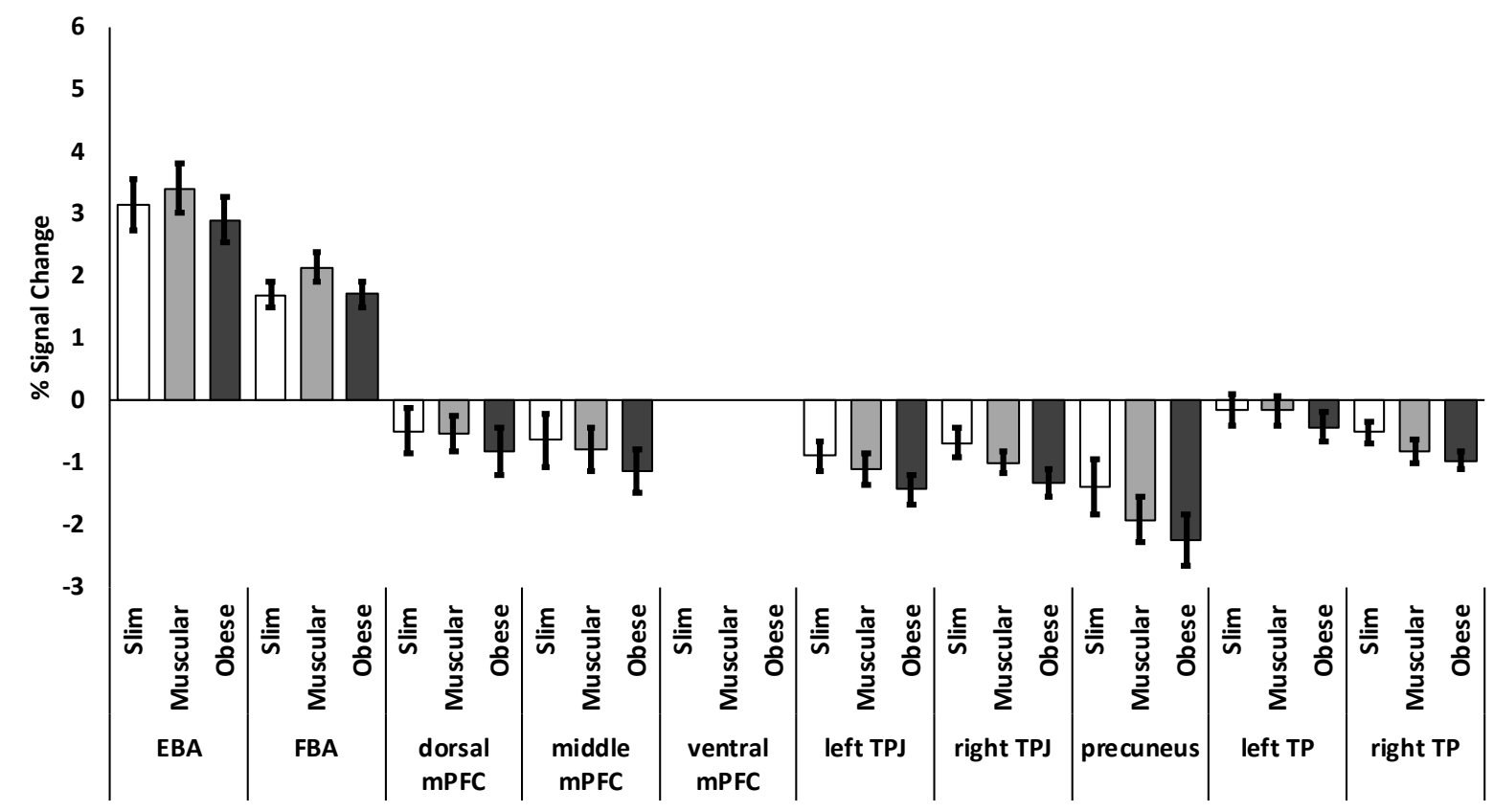

Supplementary Figure 1. Percent signal change for each body condition compared to fixation across body network and theory-of-mind network functional regions of interest. No data are reported for ventral mPFC because less than $25 \%$ of participants' localiser data showed responses in this region. Error bars are standard error of the mean. 
Supplementary Figure 2. Percent signal change data in functional regions of interest for

Experiment 2.

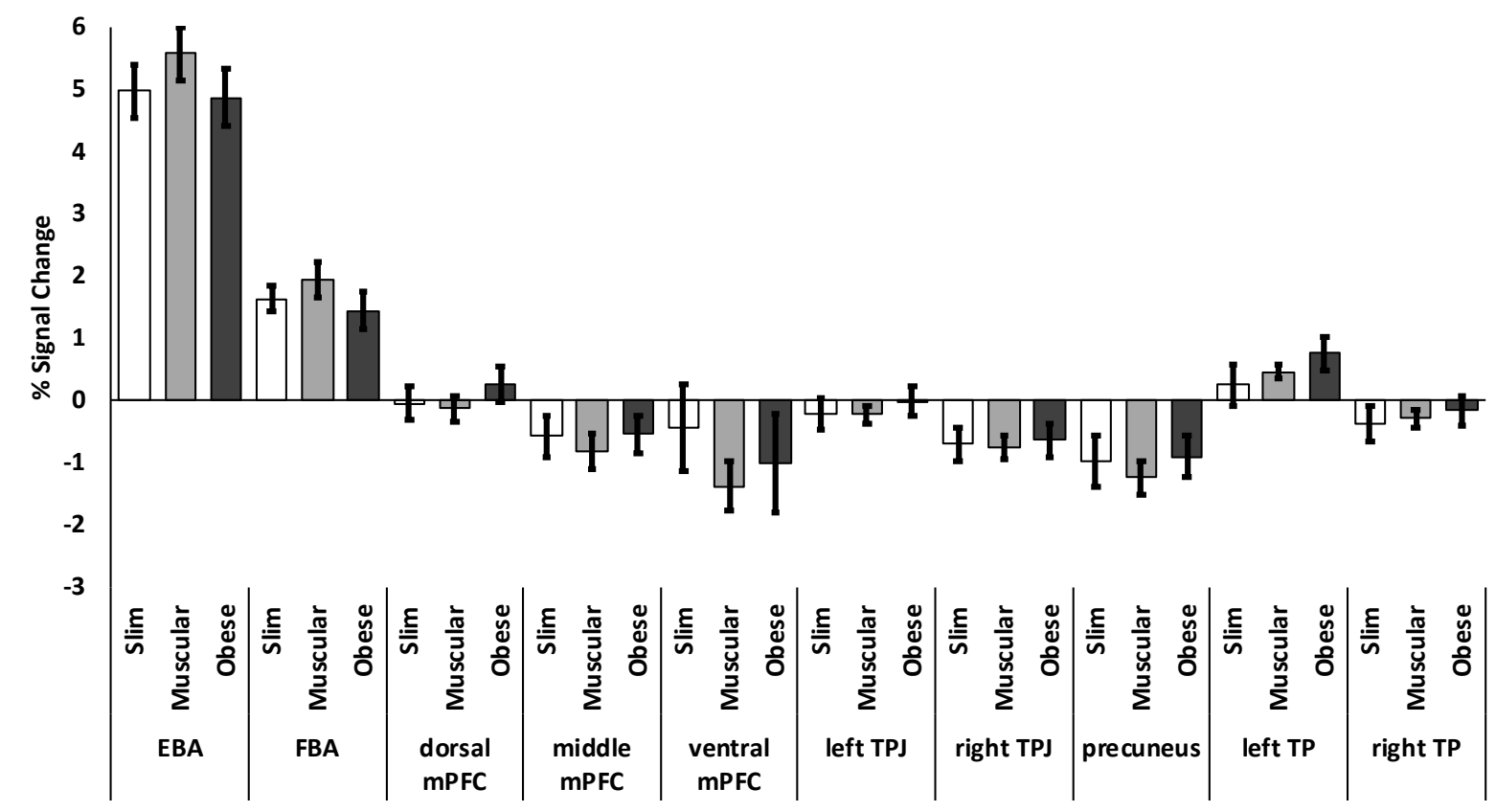

Supplementary Figure 2. Percent signal change for each body condition compared to

fixation across body network and theory-of-mind network functional regions of interest. Error bars are standard error of the mean. 


\section{Supplementary methods}

Selection and validation of stimuli: To select and validate stimuli, we ran two behavioural pilot experiments requiring participants to make socially-relevant judgments about silhouettes either presented under unlimited viewing conditions (Pilot 1) or presented briefly (Pilot 2). The participants in pilot experiments did not complete the fMRI study. First, we made series of body images that represented three different body shapes: muscular, obese, and slim. These categories were chosen so that we could compare the perception of bodies where a social evaluation is more extreme (muscular and obese) to a body where a social evaluation is relatively neutral (slim). Because the focus of our research question was on body shape only, we used body silhouettes with heads removed (see Figure 2). Bodies were selected to have a posture that was as neutral as possible (no crossed arms or slouching postures). Images were gathered from various websites, converted into silhouettes, and cropped using GIMP 2.8 (www.gimp.org). To validate that our stimuli were indeed socially evaluated differently, in two separate experiments we asked participants to rate bodies. Stimuli were presented using an iMac computer and Matlab software using Psychtoolbox 3.

In both pilot studies, all bodies were presented upright as well as inverted. Inverted bodies were included to address an additional question (not reported here). All analyses reported here are based on upright bodies. In pilot Experiment 1, 14 participants evaluated 85 upright bodies by rating them on how well the statement matched the image of a body (with 1 being 'completely disagree' and 9 being 'completely agree'). Like prior work on the evaluation of faces (e.g., Kramer and Ward 2010), statements were taken from Big-5 personality measures (Extraversion, Conscientiousness, Agreeableness; Donnellan et al. 2006), as well as physical health (Ware et al., 1996). For instance, to assess physical health, participants rated how well each body matched the statement "Accomplishes less due to health problems". Participants completed one of two versions of the task. Both versions were 
identical with the exception of the content of the questions that were asked. In each version, two questions (one positive and one negative) were asked for each of the four measures, resulting in 8 questions. Each question was asked for each body. Ratings for each condition were compared using a repeated-measures Analysis of Variance, and subsequently in two planned comparisons (slim vs. muscular and slim vs. obese). All results are summarised in Figure 2.

In pilot Experiment $2(\mathrm{n}=23)$, we wanted to find out whether these silhouettes gave rise to a social inference during a brief presentation, which would be more akin to conditions during the fMRI experiment. To do so, each body was presented for $330 \mathrm{~ms}$, after which it was backward masked for $300 \mathrm{~ms}$. The question then remained on screen until a response was made. Participants were asked to assess how confident they were about the answer they gave. Participants completed one of two versions of the task. These were identical, with the exception of how the bodies were paired with the questions. In each version, two questions (one positive and one negative) were asked for each of the four measures, resulting in 8 questions. Each of the bodies was rated on all measures.

Functional region of interest analysis: To perform functional region of interest (fROI) analyses, we used the Group-constrained Subject-Specific (GSS) approach (Fedorenko et al., 2010; Julian et al., 2012; Nieto-Castañón \& Fedorenko, 2012). For GSS analyses, the spm_ss toolbox was used, which runs in SPM using Matlab (http://web.mit.edu/evelina9/www/funcloc.html). fROIs were defined using 1) each individual's activation map for the localiser tasks, and 2) group-constraints or masks. These masks refer to a set of "parcels", which demarcate areas in the brain where prior work has been shown to exhibit activity for the localiser contrasts.

Two sets of fROIs were defined: Body network fROIs that respond to images of bodies more than other object categories (Downing et al., 2001) and ToM-network fROIs that 
support processes associated with theory-of-mind (Saxe \& Kanwisher, 2003). For the body network fROIs, right FBA and EBA were defined using average coordinates taken from our own body localiser data. For example, for GSS analyses in Experiment 1, we used the group average coordinates from Experiment 2's body localiser data. Then for Experiment 2's GSS analyses, we used localiser data from Experiment 1. Therefore, the data used for defining fROIs was independent from the data used for estimating responses (Kriegeskorte et al., 2009). We placed 10mm spheres centred on the average coordinates for FBA and EBA.

For the ToM-network, six parcels were derived from a group-level map from 462 participants for the False Belief $>$ False Photograph contrast (Dufour et al., 2013). These regions included the dorsal, medial, and ventral prefrontal cortex (DMPFC, MMPFC, VMPFC), bilateral temporoparietal junction (TPJ) and precuneus. Bilateral temporal poles were identified in a different manner because they were not identified in isolation in the map produced by Dufour and colleagues (2013). Instead, we identified coordinates for the temporal poles using ToM localiser data in a similar manner to the way body network fROIs were selected. That is, for GSS analyses in Experiment 1, we used the average temporal pole coordinates from Experiment 2's ToM localiser data. For Experiment 2's GSS analysis, we used average temporal pole coordinates from Experiment 1's ToM localiser data. Again, we centred $10 \mathrm{~mm}$ spheres on the group average coordinates for right and left temporal pole.

For each individual participant, these masks were used to constrain the selection of subject-specific fROIs. For each individual and within each body fROI, voxels that passed a threshold $(\mathrm{p}<0.001$, uncorrected $)$ in the Bodies $>$ Cars contrast were defined as that individual's fROI. Similarly, for each ToM fROI, the Belief $>$ Photo contrast was used and voxels that passed the same threshold were selected in each individual participant separately. All runs of the localiser tasks were used to define fROIs in each individual. Percent signal change (PSC) values were extracted from all fROIs and responses were estimated for three 
separate contrasts: Slim > Fixation; Muscular $>$ Fixation; Obese $>$ Fixation. As implemented in GSS, statistical tests were performed on the PSC values using standard Student's t-tests.

One-sample t-tests were performed to investigate the response of the body and ToM network fROIs. False Discovery Rate (FDR) multiple comparison correction $(\mathrm{p}<.05)$ was used to correct for the number of fROIs in each functional network. For Experiment 1, the fROI results are reported in Supplementary Table 4 and Supplementary Figure 1 and for Experiment 2 the fROI results are reported in Supplementary Table 5 and Supplementary Figure 2. The data are also made available online to guide future experiments (https://osf.io/p4sbr/).

\section{Supplementary References}

Dufour N, Redcay E, Young L, Mavros PL, Moran JM, Triantafyllou C, Gabrieli JD, Saxe R. 2013. Similar brain activation during false belief tasks in a large sample of adults with and without autism. PloS One. 8:e75468.

Kriegeskorte N, Simmons WK, Bellgowan PS, Baker CI, 2009. Circular analysis in systems neuroscience: the dangers of double dipping. Nat. Neurosci. 12:535-540.

Fedorenko E, Hsieh PJ, Nieto-Castañón A, Whitfield-Gabrieli S, Kanwisher N. 2010. New method for fMRI investigations of language: defining ROIs functionally in individual subjects. Journal of neurophysiology. 104:1177-94.

Julian JB, Fedorenko E, Webster J, Kanwisher N. 2012. An algorithmic method for functionally defining regions of interest in the ventral visual pathway. Neuroimage. 60:2357-64.

Nieto-Castañón A, Fedorenko E. 2012. Subject-specific functional localisers increase sensitivity and functional resolution of multi-subject analyses. Neuroimage. 63:164669. 